\title{
Unpacking Non-Dualistic Design: The Soma Design Case
}

\author{
KRISTINA HOOOKK, Media Technology and Interaction Design, Royal Institute of Technology \\ STEVE BENFORD and PAUL TENNENT, Mixed Reality Lab, The University of Nottingham \\ VASILIKI TSAKNAKI, Digital Design Department, IT University of Copenhagen \\ MIQUEL ALFARAS, Universitat Jaume I and PLUX S.A.
}

JUAN MARTINEZ AVILA, CHRISTINE LI, and JOSEPH MARSHALL, Mixed Reality Lab, The

University of Nottingham

CLAUDIA DAUDÉN ROQUET, Lancaster University

PEDRO SANCHES, ITI/LARSYS, ARDITI

ANNA STÅHL, RISE - Research Institute of Sweden

MUHAMMAD UMAIR, Lancaster University

CHARLES WINDLIN, Media Technology and Interaction Design, Royal Institute of Technology

FENG ZHOU, Mixed Reality Lab, The University of Nottingham

\begin{abstract}
We report on a somaesthetic design workshop and the subsequent analytical work aiming to demystify what is entailed in a non-dualistic design stance on embodied interaction and why a first-person engagement is crucial to its unfoldings. However, as we will uncover through a detailed account of our process, these first-person engagements are deeply entangled with second- and third-person perspectives, sometimes even overlapping. The analysis furthermore reveals some strategies for bridging the body-mind divide by attending to our inner universe and dissolving or traversing dichotomies between inside and outside; individual and social; body and technology. By detailing the creative process, we show how soma design becomes a process of designing with and through kinesthetic experience, in turn letting us confront several dualisms that run like fault lines through HCI's engagement with embodied interaction.
\end{abstract}

CCS Concepts: • Human-centered computing $\rightarrow$ Interaction design theory, concepts and paradigms; Additional Key Words and Phrases: Soma design, somaesthetics, first person

\footnotetext{
Authors' addresses: K. Höök and C. Windlin, Media Technology and Interaction Design, Royal Institute of Technology, P.O. Box 1212, Stockholm 10044, Sweden; emails: \{khook, charles.windlin\}@kth.se; S. Benford, P. Tennent, J. M. Avila, C. Li, J. Marshall, and F. Zhou, Mixed Reality Lab, The University of Nottingham, Jubilee campus, Nottingham, UK; emails: \{steve.benford, paul.tennent, juan.martinez-avila, christine.li, joe.marshall\}@nottingham.ac.uk, pszfz@exmail. nottingham.ac.uk; V. Tsaknaki, Digital Design Department, IT University of Copenhagen, P.O. Box 1212, Copenhagen 10044, Denmark; email: vats@itu.dk; M, Alfaras, Universitat Jaume I, Castelló de la Plana, Spain, PLUX S.A., Lisbon, Portugal; email: miquel.alfaras@uji.es; C. D. Roquet and M. Umair, Lancaster University, Bailrigg, Lancaster, UK; emails: \{c.daudenroquet1, m.umair7\}@lancaster.ac.uk; P. Sanches, ITI/LARSyS, ARDITI, Funchal, 9020-105, Portugal; email: pedro.n. sanches@tecnico.ulisboa.pt; A. Ståhl, RISE - Research Institute of Sweden, Kista 16428, Sweden; email: anna.stahl@ri.se. Permission to make digital or hard copies of all or part of this work for personal or classroom use is granted without fee provided that copies are not made or distributed for profit or commercial advantage and that copies bear this notice and the full citation on the first page. Copyrights for components of this work owned by others than ACM must be honored. Abstracting with credit is permitted. To copy otherwise, or republish, to post on servers or to redistribute to lists, requires prior specific permission and/or a fee. Request permissions from permissions@acm.org.

(C) 2021 Association for Computing Machinery.

1073-0516/2021/11-ART40 \$15.00

https://doi.org/10.1145/3462448
}

ACM Transactions on Computer-Human Interaction, Vol. 28, No. 6, Article 40. Publication date: November 2021. 


\section{ACM Reference format:}

Kristina Höök, Steve Benford, Paul Tennent, Vasiliki Tsaknaki, Miquel Alfaras, Juan Martinez Avila, Christine Li, Joseph Marshall, Claudia Daudén Roquet, Pedro Sanches, Anna Ståhl, Muhammad Umair, Charles Windlin, and Feng Zhou. 2021. Unpacking Non-Dualistic Design: The Soma Design Case. ACM Trans. Comput.-Hum. Interact. 28, 6, Article 40 (November 2021), 36 pages.

https://doi.org/10.1145/3462448

\section{INTRODUCTION}

HCI has a longstanding interest in embodied interaction [20], but it often misses out on the body itself. What is distinctive and challenging about more deeply connecting our bodies to computers? Recent work has begun to adopt a more overtly body-focused agenda [54]. This includes work on exergames [56], affective loops [33], implicit interactions [44], faceless interfaces [43], uncomfortable interactions [8], estrangements [102], movement-based games [41], interpersonal touch [57], and fidgeting interactions [46]. While various theories of embodiment provide some of the underpinnings to help guide this design work, they miss ways of speaking about the actual body and how processes like affect, movement, and thinking are intertwined-one generating the other.

One growing stance in HCI engages with philosopher Shusterman's concept of somaesthetics [87]. By somaesthetics Shusterman refers to our ability to engage with and deepen our appreciation of sensory experiences. What appeals about this stance to us, as interaction design researchers, is how the somaesthetic project is not only an analytical stance, but also a pragmatic and practical endeavor, thereby providing a direction for the design work, as well as ideals to strive for in design.

Somaesthetics underpins the approach of Soma Design within HCI, which is distinguished by four key characteristics. First, Soma Design foregrounds the lived body of the designer, involving extensive bodily experience through personal practice. Particularly, projects can be driven by different approaches to how the bodies of the designers, and those who we design with, are understood: in the third-person (I-It), second-person (I-You), or first-person (I-Me). These perspectives are rooted in Merleau-Ponty's phenomenology of the body [58]. Note how it is not only the firstperson perspective that is a 'felt' subjective stance. Merleu-Ponty's understanding of the secondperson perspective was as a deeper, bodily felt, awareness in which the other's experience takes possession of me-we grasp the meaning of the other's expression through feeling it. And even when we attempt to take a third-person perspective on our own bodies-seeing a limb or a muscle from the 'outside'-we are always, simultaneously experiencing it from within. Merleau-Ponty speaks of "double sensation": we live it at the same time as we think about it. A second characteristic of Soma Design is that it adopts a holistic stance towards the mindbody rather than building on the dualist schools of thought that separate the cognitive from the physical and that have underpinned much previous work in HCI. Third, it emphasises the aesthetic appreciation of bodily experience, striving for an altered sensibility with respect to one's own somasensory experiences. And fourth, following on from this, it is an active stance, inviting us to seek out new bodily practices and, in its application within HCI, new digital technologies to support these. Soma Design therefore encourages us to design for deepening aesthetic appreciation and meaning-making from a position as sentient, subjective selves. Through engaging somatically with the digital materials we design with, their somaesthetic potential is revealed and can be shaped into felt experiences relevant to the design aims.

Soma Design has been applied to designing for: mindfulness [89], ways of extending on the body, such as adding another sense or a limb (or tail!) [93], alleviating issues with mental health [77], pain regulation [48], dance [81], art [47, 82], female health [13], as well as designing mundane objects such as remote controls [55, 68] or household appliances [99]. 
The contribution of this article arose from a Soma Design conversation which brought together two research groups, both interested in exploring bodily interactions but from different perspectives. This involved an initial collective workshop to apply the Soma Design approach to four ongoing projects focusing on balance and uncomfortable interactions, followed by several further design workshops to develop specific insights and prototypes that emerged. In what follows, we will refer to the Soma Design studio as the group that is concerned with developing and applying Soma Design methods, and the Mixed Reality studio as the second group that explores artistic and entertainment applications of bodily interactions.

The meeting between the two studios, and perhaps more importantly, the analysis in repeated meetings over one and a half years, articulating the different insights and somatic engagements, challenged what it means to engage in a first-person-driven, non-dualistic design stance. It allowed us to better understand how first-, second-, and third-person perspectives can be interwoven in design work and that they are all needed when we engage with our whole soma. Below we document how we traverse these three design perspectives, both back and forth and holding them at the same time, and how all of them, together, leads to a non-dualistic design stance. This analysis in turn allows us to better discern the nature of the mind-body divide by recognising three further overlapping "mindbody" perspectives: separation of mind from body; separation of conscious mind from subconscious mind; and separation of material body from the external world. It allows us to better comprehend how these mindbody perspectives are also fluidly negotiated, sometimes by moving back and forth between oppositional poles, but also by training oneself to hold them simultaneously as part of the Somaesthetic discipline of acquiring an altered aesthetic appreciation of bodily experience. A Soma Design approach allows the felt experience to take the front seat, helping us to attend to the connections between body, mind, and emotion; attend to that which is conscious as well as subconscious; as well as attending to, or even letting the borders of our body's separation from the world to be dissolved. Finally, the meeting of the two studios revealed how strategies of defamiliarization and refamiliarization can enable designers (and potentially users too) to negotiate this complex web of perspectives. Ultimately, a fresh look at defamiliarization and refamiliarization has led us to contribute the idea of multiple and flexible perspectives on bodily interaction that can be interwoven as designers wrestle with the challenge of pursuing a holistic approach. Our resulting discussion contributes both design perspectives (first-, second-, and third-person) as a path to mindbody perspectives (dissolving the borders of mind-body, conscious-subconscious, and body-world).

\section{RELATED WORK}

\subsection{Embodied Interaction}

Our interest in embodied interaction focuses on the knotty question of how to pursue a holistic view of bodily experience through a first-person design approach. In order to better understand the challenge we first consider the alternative, various examples of dualistic thinking that have attempted to separate out different aspects of the problem and that have been influential in HCI. We also consider various responses to these that have called for a more holistic approach. There are several related dualisms to consider.

The first is the question of mind-body dualism that has riven philosophy throughout its history, from Aristotle [32] and Plato [21] who argued for the existence of a "soul" that was separate from the body to Descartes' [18] famous argument for separating mind from brain. This mind-body dualism is reflected in much of HCI's foundational thinking about interaction, for example, in the separation of cognitive goals from physical systems, the so-called gulfs of execution and evaluation in Norman's [64] "cognitive engineering”. Others have argued against mind-body dualism, 
calling for a holistic stance on "embodied interaction". Building on the foundations of both tangible and social computing, Dourish [20] drew on the philosophy of phenomenology to reject dualism and instead argue for an account of interaction in which users create and communicate meaning through their embodied experience of systems in the world. One of Klemmer's [49] five themes for designing embodied interaction, "thinking through doing", argues that thought (mind) and action (body) are deeply integrated in co-producing learning and reasoning. Höök's [33] work on affective loops argues for involving both body and mind "inseparably" in the design of embodied and affective systems. Mueller et al. articulate four perspectives on the design of exergames through recognition of the "responding body", "moving body", "sensing body", and "relating body" [60] Höök et al. [36] observe that "writings about embodied interaction, the actual, corporeal body- our muscles, the way we move, our postures-has been notably absent", which inspired them to turn to Shusterman's [87] body-conscious philosophy of somaesthetics that we explore in this article [34].

A second relevant notion of dualism is to be found in dual-process theories from psychology. In broad terms, this focuses on a separation of conscious from subconscious within the mind. Psychologist Daniel Kahneman [45](2011) has proposed classifying mental processes that govern human behaviour into two categories of thinking known as the "automatic mind" (more formally called system 1) and the "reflective mind" (called system 2). System 1 thinking has been characterised as being fast, parallel, and automatic, requiring little or no effort, whereas system 2 has been described as effortful, slow, serial, and working in a controlled fashion. A planned decision is typically considered as system 2 thinking, whereas an immediate reaction such as "disgust" corresponds to system 1 . However, the two systems interact with each other, with system 1 suggesting feelings, impressions, and intuitions to system 2 that may be directly adopted with little modification (ibid).

This kind of dual process thinking and especially the idea that we can design for bodily "automation", pushing down processing to the system 1 thinking, has been introduced several times before in HCI. In 1987, Alan Kay described how he, together with the team at Xerox, invented the desktop metaphor. Kay recalls watching a TV show in which an instructor taught a woman who had never played tennis before to perform a forehand stroke, backhand stroke, and serve in twenty minutes. By distracting her rational reasoning, her system 2, by making her sing and chatting to her, the instructor allowed other parts of her self to relax into simple imitation behaviors-key to the behaviour of all social animals, especially primates. Kay's idea was that it should be possible to replace the command-based interfaces of computers at the time. A command-based interface requires remembering the names of commands, learning a whole vocabulary, almost learning a new language. After seeing the tennis player learn so quickly, Kay thought it would be better to make commands by gestures, physical, movement-based acts paired with clear feedback-as in, for example, point-and-click or drag-and-drop. This in turn frees up our more linguistically oriented, conscious thinking to perform other tasks.

A widely studied technique for driving system 1 thinking is to deliver subliminal stimuli which fall below the level of conscious awareness [16]. This dualism has been adopted by researchers from psychology and behavioural economics who are exploring the challenges and possibilities for behaviour change, for example in Thaler and Sunstein's influential "nudge theory" [97], who have shown that subtle changes in behaviours can occur without the human being aware of them, leading to distinctions between mindful and mindless thinking [51]. HCI researchers have incorporated such ideas into the theoretical underpinnings of persuasive computing [71], inspiring the approach of "mindless computing" in which persuasive technologies subtly influence behaviours without conscious awareness, for example, through plates whose lighting changes the colour of food or gently pitch shifting people's voices when they speak [1].

Lately, with the turn towards internet of things and ubiquitous technology, HCI has explored implicit interactions [83]. The quest for new relationships between mind and body in interaction 
design is also reflected in Ju and Leifer's [44] notion of implicit interactions in which the attention demanded by a system moves between being foreground and background, and Wakkary et al.'s [101] notion of unconscious interaction that arises from the "goodness of fit" of designs that are both open-ended and lived-with. Serim and Jacucci [84] further develop implicit interaction as an analytic concept in an attempt to unpack and systematize it. They review the various meanings of implicit, including unintentional, background, unaware, unconscious, and as "implicatures" (indirect speech acts), leading them to propose an "intentionality-based" definition of implicit interactions in which the "appropriateness of a system response to the user input (i.e., an effect) does not rely on the user having conducted the input to intentionally achieve it." Benford et al. [9] argue that humans may undertake journeys through a space of control defined by the three dimensions of surrender of control, self-awareness of control, and looseness of control when contesting control with embodied and increasingly autonomous systems. Persuasive computing in turn [71], builds entirely on addressing those subconscious, visceral, processes, letting persuasive technologies subtly influence behaviours without conscious awareness [1].

An alternative psychological theory to that of Kahneman and other cognitivists, was formed by Varela, Vermesch, and others based in the phenomenology by Husserl [17, 85]. In their philosophy, human cognition and consciousness are enacted as a consequence of (1) the body, both as a biological system and as personally experienced, and (2) the physical world in which consciousness is enacted. Husserl described consciousness as having three phases: primal impressions - what we experience in the moment, slipping away from consciousness as soon as the moment is past; retention -the memories of what happened in the moment; and finally, protentions, the future-oriented counterparts of retentions. Through what has been named micro-phenomenological interviews [69], we can bring the retentions into focus in order to surface the unrecognised, unnoticed, pre-reflective aspects of a lived experience, helping to make it clear in the interviewee's mind-reporting back on all the complex mixtures of cognitive, somatic, emotional, or social experiences unfolding both in the particular moment (synchronic) as well as over time (diachronic).

This is why some first-person researchers in HCI have used micro-phenomenology as a method to assess user experience [73]. As we shall see later, Soma Design has the same roots, relying on an embodied philosophy, but adding attention to aesthetic experience as described in theories of pragmatism.

The embodied philosophy brought attention not only to the body, but also to the physical world in which we act. This pertains to the third dualistic notion that is also relevant here, which separates human thinking and intelligence from the environment. As shown through studies in disciplines ranging from psychology to neuroscience or evolutionary biology, intelligence is enacted in action [86, 90]. Although we approach situations with previously learned behaviour patterns or instinctive behaviours, we always adjust them dynamically to fit the situation at hand. Without dynamic adjustments, we would not be able to deal with changes in the environment. To scholars in HCI, this resonates with, for example, Lucy Suchman's [90] work on plans and situated action. Human action is "essentially situated and ad hoc improvisation," responding to situations as they arise [90]. It also resonates with the work on affordances [28, 65] and with the shift towards seeing affect as an important part of what creates rational, intelligent action $[15,52,70]$.

In a similar vein, there are those who have challenged the separation of the physical body from its wider material environment. Conventionally, the skin is considered the boundary of the body, one way of defining the bodily self. We can see, i.e., perceive with our eyes, our "external", fleshy body-our moving limbs and parts, and our skin as the boundary between our "external" and "internal" body-our organs, cells, muscles and so on -which we cannot see but instead feel or imagine. In HCI, the body has been primarily looked at as a moving, living, non-reflected entity, 
hence the focus has been on "intuitive" gestures [63] and movements for interacting with all kinds of technologies e.g., robots [29], games [38], media [31], vehicles [67], and data [27]. This is not of course universal-work such as [76] shows that gestures on their own may be less than "intuitive" because of the lack of feedback, and thus propose the direct manipulation of external objects as being "more intuitive". At the same time, visions of integrating technology with the body, stemming from the very early idea of the cyborg as a hybrid between a human and a machine [14], have been influencing interaction design research. Many in the field of HCI and related disciplines have argued for integrative views of humans and technology through developing, for example, bodyworn computers or robotic devices that have the potential to "extend the malleable nature of our self-image" [53]. Concepts such as augmentation [39] and integration [23, 24, 61] depict humans and computers acting in symbiosis. In the case of integration, this symbiosis can be articulated in two dimensions [61]: The first is agency, where machines and humans can take turns leading the interaction; the second is scale, where machines and humans can be integrated at different levels, e.g., under the skin, on the skin, beyond the skin. Nowadays there are various technologies that operate above or on the skin (wearable) [100], beyond the skin (voice, gesture, and other "remote" interactions) [11, 72] and also inside the skin (implanted, edible) $[3,30]$.

Contemporary theories of feminist technoscience that have influenced research in HCI, argue for a vital materialist account of bodies, as a more radical displacement of the human subject than phenomenology has done [10]. Such a view considers agency as "being distributed across an ontologically heterogeneous field, rather than being a capacity localized on a human body or in a collective produced (only) by human efforts" (ibid, p.23). This view on the world argues for breaking down boundaries and dichotomies, and instead considering all the material forms that surround us, including bodies and even microorganisms living inside us, as part of the same assemblage that is in constant flux and reconfiguration. Soma Design theory, even if not referring directly to a vital materialist view on the world and bodies, argues for a non-dualistic somaesthetic perspective in design [34]. This perspective promotes a deepened awareness of and engagement with the bodymind - an integration of emotion, aesthetics, body, values, cognition, and movement [34]-both for designers in the design process and users in interaction.

To draw this thread together, there are multiple examples of dualistic thinking that have been influential in $\mathrm{HCI}$, but also many counter examples that argue for adopting a more holistic stance. But how does one engage a more holistic stance in practice? The approach that we explore in thisarticle is through the application of Soma Design.

\subsection{Soma Design}

2.2.1 Somaesthetics. Soma design builds on the somaesthetic project proposed by philosopher Professor Richard Shusterman, where the concept somaesthetics combines the term soma with aesthetics. By soma he refers to "the living, sentient, purposive body-as the indispensable medium for all perception" [88]. That is, soma refers to the integration of body, movement, emotion and thought, recognising and putting the subjective self at the core. By aesthetics Shusterman refers to our ability to engage with and deepen our understanding of sensory experiences with all our senses. He approaches aesthetics as an active skill, an ability to appreciate our experiences, one that can be trained and sharpened. Shusterman builds upon Dewey's [19] argument that aesthetic quality is not an inherent property of an object, but rather the result of active engagement and experience. But where Dewey emphasizes the unique, romantic, and beautiful, Shusterman understands somaesthetics as the critical and meliorative study of appreciative perception-not only of the pretty, but also the ordinary or even the disturbing. He argues that if we develop our perception and senses through close attention to our experiences, we can reap from them more richness, depth, and interest. 
2.2.2 Soma Design. Soma Design builds on this active stance towards aesthetics as a skill. Somaesthetics provides not only an analytical stance, but also a pragmatic and practical endeavour thereby offering a direction for the design work, as well as ideals to strive for in design. We can design for deepening understanding and meaning-making from a position as sentient, subjective selves. Through engaging somatically with the digital materials we design with, their potential to deepen our aesthetic appreciation is revealed and can be shaped into the felt experiences relevant to the design aims.

A common misunderstanding of somaesthetics is that it only focuses on the inwards-facing, slow, meditative experiences as we have seen several such designs. But attending to your senses and deepening your aesthetic appreciation of the world is not solely an engagement with the pleasurable, but also with displeasures, beats, rhythms, and richness of the living, felt, bodily subjectivity-our human condition. Not only the "nice," beautiful, or fine arts cultural experiences, but all sorts of experiences: beautiful, ugly, painful, shallow, exhilarating, utilitarian/work-oriented, habitual, and non-habitual behaviours.

A Soma Design process can (jokingly) be described as "stop talking - start feeling". This stands in contrast to the predominantly visual, verbally-oriented design processes mostly employed in the interaction design field, such as creating Personas, brainstorming with post-it notes, wireframes, and so on. Höök frames the difference as: "the qualitative shift required, from a predominantly symbolic, language-oriented stance, to an experiential, felt, aesthetic stance permeating the whole design and use cycle" [34].

In the soma tactics, there is a strong emphasis on the first-person perspective of the designer [35] and on movement, emotion, and reasoning as one. These somaesthetic design tactics can help a designer train their aesthetic sensibility, their ability to appreciate and discern those interactions that touch us. Let us now briefly introduce three tactics that were employed in the workshop we will report on below.

The first focuses on training one's aesthetic appreciation of somatic processes. There are many soma awareness exercises that can serve this purpose. In the workshop, we performed body-scans, Feldenkrais exercises [25], as well as contact improvisation dance. In a body scan as well as in a Feldenkrais exercise, the instructor will guide and direct a participant's focus and attention, for example, toward specific bodily or sensory sensations. This form of subtle guidance relies on the interplay between two different concepts introduced by William James (1905): change and interest. Change refers here to the importance of subdividing the bodily experiences into more specific areas or functions and then engaging in activities that shift focus from one area to another and back, in order to provide a more nuanced and rich perception of fine-grained movements. The notion of interest deals with finding a way to sustain one's focus on one body part or area. We easily get distracted, our minds wander, to maintain attention it is important to spur curiosity and attention to somatic signs and signals. Apart from focusing on one's own somatic signs and signals, we did similar exercises where we used bits and pieces of technology and tried to discern their effects on our senses [103].

The second tactic used in the workshop was to engage with defamiliarisation methods. This can also be done in many different ways: one can engage in asymmetrical movements, perform habitual movements in the non-habitual manner (e.g., folding your arms the other way around), or make movements "strange" [102]. These strategies reveal not only what movements we might be doing habitually, but they also reveal habitual norms, attitudes, and thought processes, as these are all enacted through our somas. Again, defamiliarisation tactics can be done both with and without technology, as we will see in some of the workshop exercises.

The third tactic is to extend one's movement repertoire. As discussed by Moshe Feldenkrais "a limited repertory of movements leads to a limited repertory of experiences" [25]. There are 
many movements we have never performed or that we might have performed as children-e.g., skipping instead of walking-but then never engage with as adults. For example, in our contact improvisation dance, we were encouraged to touch and move with others in playful manners, similar to how we played as children.

Each of these three tactics concern how to engage with one's own soma, making movement/emotion-experiences clearer in our minds, attending to all the small nuances. Once they become "clearer" in our minds, we can start to perceive all sorts of nuances. And with these nuances comes a sensitivity to design and what some particular design might do for us.

\section{APPROACH}

Our approach involved an engagement between the two studios over the course of more than a year. We begin by describing the two studios before presenting the process this followed.

\subsection{The Two Studios}

We will employ Redström's [75] account of a "design program" to characterise the two research groups, or, as we will refer to them, the two design studios. Redström argues that the way we frame design knowledge can range from pointing to a single, specific design, to describing a larger and more encompassing program, which forms a consistent universe of design knowledge or explorations, incorporating certain aesthetics and interaction patterns, and perhaps spurring certain end-user behaviors or experiences. The two studios, Soma Design and Mixed Reality, can be characterised as having different programs, different aesthetic axioms, as their starting point.

The Soma Design studio approaches their design work on engaging in bodily exercises such as Feldenkrais or Contact improvisation dance to achieve an awareness of our somas-improving on and understanding the connections between movement, emotion, and thinking-and what interactive technologies may afford. They have built applications for increasing body awareness [36], improving female health such as increasing menstruation cycle awareness [13], pelvic floor engagements [6], and applications addressing mental health through creative design processes [77].

The Mixed Reality studio has a long history of designing and studying artistic and entertainment applications of computing spanning theatre, music, museums, and games [94]. The studio works with diverse technologies from immersive virtual and augmented reality through to embedded, tangible, and wearable interfaces. What unifies their work is a dedication to collaborating with external artists and other creatives to help realise new artistic works that can then be studied as they tour to cultural venues. Their conceptual interests lie in understanding and articulating how these artists often create thought-provoking, ambiguous, intense, thrilling, and sometimes challenging experiences, before translating this knowledge into concepts aimed at the wider HCI community. A key element of their agenda involves foregrounding and even designing for discomfort as part of the inherent challenge, thrill, and provocation of such experiences.

\subsection{The Process}

We began by bringing the two studios together for a two-day long joint workshop in December 2018, hosted at the Mixed Reality studio and orchestrated by the Soma Design studio, during which Soma Design methods were applied to four pre-selected projects from the Mixed Reality studio. All four projects were relating to balance and proprioception in different forms. The workshop involved 14 participants, all authors of this article with backgrounds spanning interaction and Soma Design, split into four groups of three or four. Table 2 shows the distribution of the groups.

In the ideation phase of a project, it is important to "lay the table" with the right materials and the right question, as these shape our design ideas. While preparing for and planning the workshop, the Soma Design studio therefore explored balance through a series of Feldenkrais lessons and 


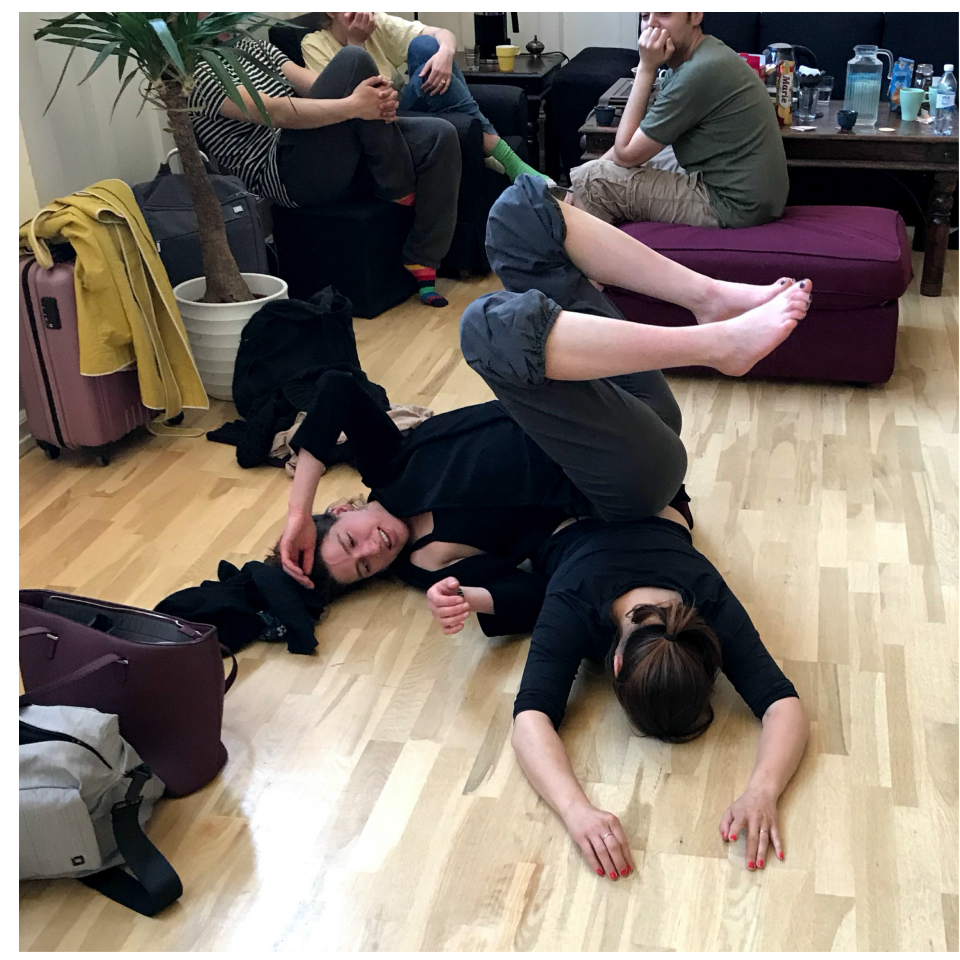

Fig. 1. Contact improvisation.

contact improvisation sessions (Figure 1). The choice of exploring balance activities through these two bodily practices was based on the Soma Design studio's familiarity with these practices from previous design processes. Additionally, exploring the topic of balance through bodily exercises, before running the workshop, was aimed to identify exercises that would gradually ease other workshop participants into experiencing balance through their bodies, with the help of sensitizing exercises. The aim was to let this guide our choice of body practices, material, and technology to bring to the workshop with the Mixed Reality studio. The Soma Design studio compiled a set of sensitizing activities focused on balance in the following sequence: Starting with an individual body scan, which is followed by an individual Feldenkrais exercise on balance, and finally advancing into Contact Improvisation exercises done in pairs or a group. From the preparations conducted by the Soma Design studio focused on exploring balance somatically, some interesting insights emerged. Contrary to commonly held beliefs, it was found that the experience of balance was not so much about holding the balance but being in balance, as a dynamic on-going process of negotiating between giving weight and taking weight. It was also found that this dynamic negotiation process happens always in relation to some reference point, such as the floor, a chair to sit on, someone else's shoulder, or a wall to lean against. Some of the key experiences that were explored included relaxing into balance, trust in yourself and others, alternating the states of being in and off balance, and daring to take risks.

To further "lay the table" with relevant materials, the Soma Design studio brought a set of technological "bits" which they referred to as Soma Bits [103] - semi-finished pieces of technology that allow participants to touch and feel the affordances of different actuators, such as vibration, heat, or inflation/deflation (Figure 2), as well as bits for sensing, such as heart rate sensors. To these, 


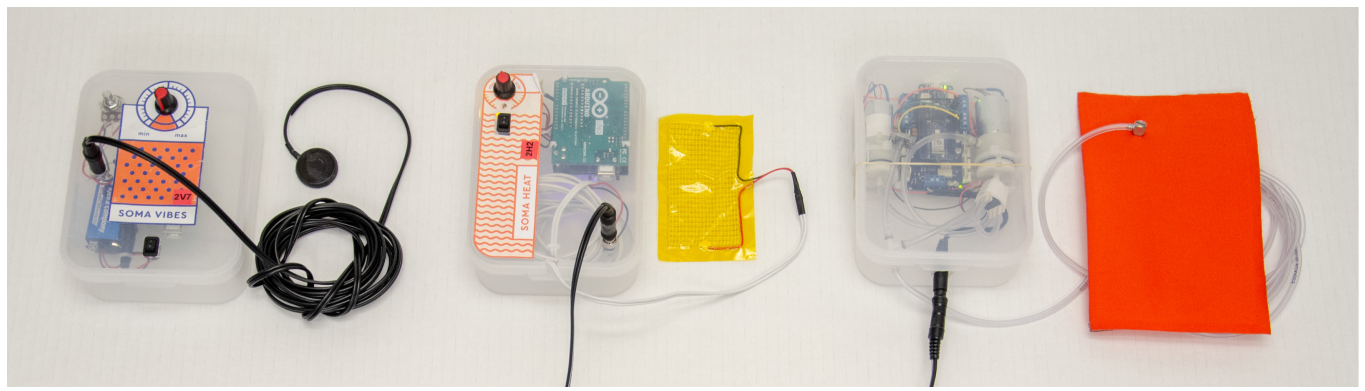

Fig. 2. Soma bits.
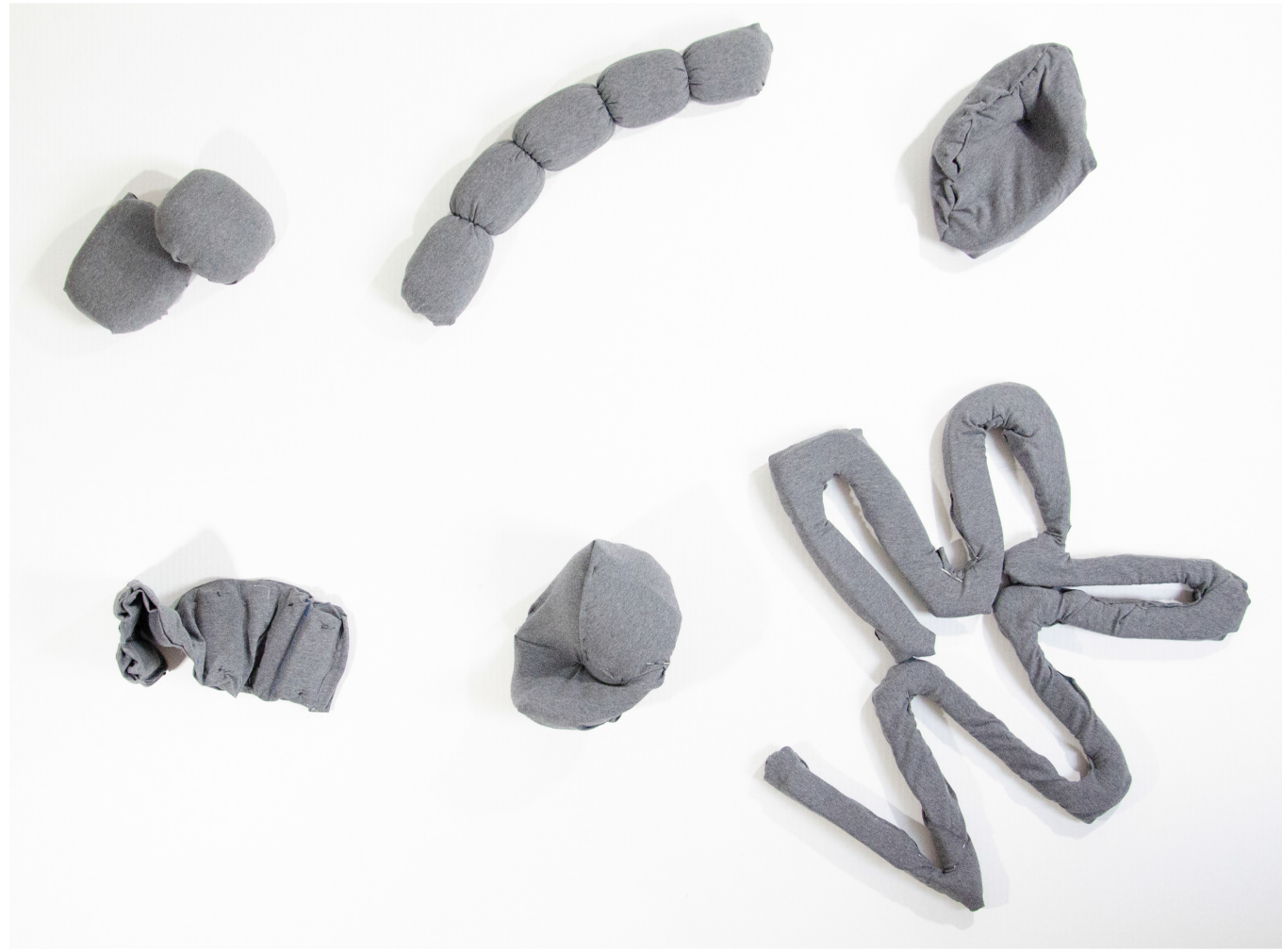

Fig. 3. Some example of soma shapes.

we added some novel bits to do with balance, such as a bit that used electromyography (EMG) to detect micro-muscle movements and sonified the output. When placed on a muscle involved in balancing, such as around the ankle, it became possible to "hear" the balancing activity [2]. In order for the Soma Bits to be played with in connection to the body, the Soma Design studio also brought Soma Shapes (see Figure 3). These are a mix of shapes of varying density-some very hard and others very soft or 'cushy'-that can follow the organic shapes of the body, specifically made for the purpose of designing with balance.

In turn, the Mixed Reality studio prepared a set of four "base" experiences, one for each group, related to the theme of balance and drawing on their ongoing research: a virtual reality balance 
Table 1. Description of Four Proto-Experiences Brought by the Mixed Reality Studio

\begin{tabular}{l|l}
\hline Name & \multicolumn{1}{c}{ Description } \\
\hline Flying Harness & $\begin{array}{l}\text { VR human flying experience, made with stage harness hanging } \\
\text { from scaffolding frame. VR experience was a simple point-to-fly } \\
\text { interaction around a city. }\end{array}$ \\
\hline Balance Beam & $\begin{array}{l}\text { VR experience of walking a balance beam, made using a real } \\
\text { balance beam (scaffolding pole) on the floor and a position- } \\
\text { matched virtual beam. Included a rotational sensory misalign- } \\
\text { ment to make balancing harder. }\end{array}$ \\
\hline Augmented Guitar & $\begin{array}{l}\text { Acoustic guitar augmented with computer recognisable pat- } \\
\text { terns. Computers and audio interfaces for sound manipulation. }\end{array}$ \\
\hline Prosthetics & $\begin{array}{l}\text { More concept than ready-made design, this was the notion of } \\
\text { 3D printing personalised prostheses for dancers. Example pros- } \\
\text { theses were brought along as inspiration. }\end{array}$ \\
\hline
\end{tabular}

Table 2. Group Members Making Up Each of the Four Teams

\begin{tabular}{|c|c|c|}
\hline Name & Experience & Research Area \\
\hline \multicolumn{3}{|l|}{ Balance beam group } \\
\hline Joe Marshall & Mixed Reality Studio Experienced researcher & Sensory misalignment \\
\hline Kristina Höök & Soma Design Studio Experienced researcher & Soma design \\
\hline Charles Windlin & Soma Design Studio PhD Student & Soma design \\
\hline Paul Tennent* & Mixed Reality Studio Experienced researcher & isalignment \\
\hline \multicolumn{3}{|l|}{ Flying Harness group } \\
\hline Christine Li & Mixed Reality Studio PhD student & Embodied interaction \\
\hline Vasiliki Tsaknaki & Soma Design Studio Experienced researcher & Soma design \\
\hline Miquel Alfaras & Soma Design Studio PhD student & Biofeedback \\
\hline Paul Tennent* & Mixed Reality Studio Experienced researcher & Sensory misalignment \\
\hline \multicolumn{3}{|l|}{ Guitar group } \\
\hline Juan Martinez Avila & Mixed Reality Studio PhD student & Encumbered interaction \\
\hline Steve Benford & Mixed Reality Studio Experienced researcher & Embodied interaction \\
\hline Anna Ståhl & Soma Design Studio Experienced researcher & Soma design \\
\hline Muhammad Umair & Soma Design Studio PhD student & Biofee \\
\hline \multicolumn{3}{|l|}{ Prosthetics group } \\
\hline Feng Zhou & Mixed Reality Studio PhD student & sthetics \\
\hline Claudia Daudén Roquet & Soma Design Studio PhD student & Iness \\
\hline Pedro Sanches & Soma Design Studio Experienced researcher & Designing with data \\
\hline
\end{tabular}

* Paul Tennent switched groups on Day 2.

beam; a virtual reality flying experience based on a physical flying harness; the concept of an augmented guitar to support rehearsal practices; and a project to design and 3D print aesthetic prosthesis for dancers. Table 1 shows a list of these proto-experiences with brief descriptions.

The first day started with a short introduction including a presentation of the schedule, the aim and topic of the workshop. This was followed by the first of several bodily activities, in this case a "body scan". This is usually performed with closed eyes and involves a set of questions to focus one's attention to particular body parts. One workshop participant from the Soma Design studio (Kristina) led the body scan activity while the rest of the participants lay on mats on the floor. To the Mixed Reality studio, this exercise was their first experience of engaging with somaesthetic appreciation skills. 
Next, a Feldenkrais exercise was facilitated by a practitioner that we invited for this purpose, as a somatic connoisseur - a practice Schiphorst argues will help a design group as the connoisseur will share expertise with the whole group [80]. Feldenkrais is a bodily activity often used by the Soma Design studio [35] for sensitizing one's body and for turning inwards and reflecting on how it feels to perform movements extremely slowly, or how it feels to perform a habitual movement in many different ways. Vasiliki had a few online meetings with the invited Feldenkrais practitioner before the workshop took place, to discuss possible exercises on balance, based on the somatic experiences and reflections emerging through the Feldenkrais and the Contact Improvisation exercises that the Soma Design studio has practiced while preparing for the workshop. One of the exercises the practitioner led and we performed was focused on experiencing how the torso balances on the bones of the pelvis when sitting on a chair: while sitting, participants made slow and subtle rotations of their upper bodies drawing attention to these bones. Verbally, she guided us through this exercise and invited us to draw our attention to the quality of the movement, to the sensation of the hard and sturdy bones balancing on the surface of the chair and to any feelings of discomfort or relaxation this experience evoked for us.

In the afternoon of the first day, participants were introduced to the Soma Bits and shapes mentioned above. Each group picked some of the Soma Bits and shapes and first explored these freely. They then began to apply them in the context of their chosen project, reflecting on how the experiences might be changed, adapted, disrupted, or subverted through the application of those Soma Bits. By placing combinations of actuators and shapes on different parts of the body, while experiencing each prototype, participants started imagining and orchestrating interactive bodily experiences while reflecting on the bodily impact of each activity.

The next workshop session included exploring what sensors could be brought to the table. Important to note here is how the first day focused on actuators and only during the second day did we couple those actuators to sensors. If sensors are introduced too early, it is easy to become distracted into only considering experiences that can be sensed-or driven by sensing, instead of working backwards from the actuation desired into figuring out which sensors may be needed to deliver that effect. We focused on capturing and reflecting on invisible aspects of sensing, such as skin conductance to detect arousal, or EMG to detect micro-muscle movements. This exploration proved pivotal mainly for the balance beam prototype group, and led to new design discoveries, as we will present in detail below.

Following the biosensing exploration, the next workshop activity was a Contact Improvisation session. Contact Improvisation is a form of improvised dancing that involves exploring one's body in relationship to others by using the fundamentals of sharing weight, touch, and movement awareness. It originates in the work of Steve Paxton, an improvisational dancer and Aikido student and was promoted by the dancer Nancy Stark Smith $[50,66]$. The Contact Improvisation exercises were led by Vasiliki and Anna, who have experience in this type of bodily practice, and who decided to bring some of the exercises focused on balance, that they have practiced in Stockholm with a Contact Improvisation connoisseur. Working in groups of two, participants engaged in activities of feeling the weight of another person's arm or leg by holding it in one's hands, or by exploring leading and following movements, building up a non-verbal communication between two people. This final bodily activity was then followed by a return to the proto-experiences of the four groups from the first day. Each group delved deeper into the experiences they were exploring and developing, through the lens of the shared balancing experiences in the Contact Improvisation exercises. Table 3 shows a complete list of the activities in the workshop.

The end of the workshop did not signal the end of the combined work of the two groups. Instead, in a series of regular online meetings and new design workshops, the two groups continued to meet in various combinations to further tease out the implications of the findings of the 
Table 3. Session Activities and their Motivations

\begin{tabular}{l|l|l|l}
\hline Activity & \multicolumn{1}{|c|}{ Led By } & Group/All & \multicolumn{1}{c}{ Motivation } \\
\hline Day 1 & Soma design researcher & All & $\begin{array}{l}\text { Introduce mixed reality group to soma design } \\
\text { methods. }\end{array}$ \\
\hline Introduction & Soma design researcher & All & Sensitise all participants to their soma. \\
\hline $\begin{array}{l}\text { Familiarising with project } \\
\text { experiences }\end{array}$ & $\begin{array}{l}\text { Mixed reality } \\
\text { researchers }\end{array}$ & Groups & $\begin{array}{l}\text { Introduction to each of the four prototype tech- } \\
\text { nologies brought by the mixed reality studio and } \\
\text { opportunity to choose groups based on interests. }\end{array}$ \\
\hline $\begin{array}{l}\text { Feldenkrais Exercises on } \\
\text { Balance }\end{array}$ & Invited practitioner & All & $\begin{array}{l}\text { Training for mixed reality studio on using soma } \\
\text { articulation techniques, further soma sensitisa- } \\
\text { tion. }\end{array}$ \\
$\begin{array}{l}\text { Soma Bits and Shapes (only } \\
\text { actuators) }\end{array}$ & Soma design researcher & Groups & Introduction of the Soma Bits to the wider group. \\
\hline $\begin{array}{l}\text { Design work on prototype } \\
\text { Day 2 }\end{array}$ & - & Groups & $\begin{array}{l}\text { Starting to add Soma Bits into original prototypes } \\
\text { and explore effects. }\end{array}$ \\
\hline $\begin{array}{l}\text { Feldenkrais Exercises on } \\
\text { Balance }\end{array}$ & Invited practitioner & All & Re-sensitisation of all to their soma. \\
\hline $\begin{array}{l}\text { Bio-sensing } \\
\text { Contact Improvisation }\end{array}$ & Soma design researcher & Groups & $\begin{array}{l}\text { Chance to explore bio-sensing technologies to- } \\
\text { gether with prototypes and explore effects. }\end{array}$ \\
\hline $\begin{array}{l}\text { Design work on prototype } \\
\text { Sharing of design work on } \\
\text { prototype }\end{array}$ & Soma design researcher & All & $\begin{array}{l}\text { Chance to consider physical sensation related to } \\
\text { other bodies. Further exploration of balance. }\end{array}$ \\
\hline
\end{tabular}

workshop. The tightrope project has since undergone further development and study with hundreds of users having tried it; the flying harness is perhaps the least explored-possibly because it requires substantial physical infrastructure, but a number of flight-oriented VR experiences have been developed as student projects. These two experiences formed the basis for a deeper analysis of how sensory misalignment can be done not only through disturbing the visual senses, but all senses [95]. The guitar group developed their design ideas into a Stretchy Strap prototype, before running a follow-up workshop where they brought forth a Breathing Guitar concept that we will return to below [5]. Finally, members of the prosthetics group went on to run a follow-up workshop with professional disabled dancers on co-designing the aesthetics of new prosthetics directly through the medium of dance.

Alongside continued work on the designs, the two studios have met frequently to analyse and discuss the workshop findings. Before delving into the outcomes of those discussions, let us turn to the design work that came out of the workshop, highlighting what type of explorations and somatic experiences were foregrounded in each project group.

\subsection{Reflections on the Workshop from the Mixed Reality Studio}

For the researchers in the Mixed Reality studio, this was the first opportunity for us to experience a method we had been aware of for some time through the wider $\mathrm{CHI}$ literature, and especially following a visit to our studio from the lead Soma Design researcher. The processes employed in the workshop seemed far removed from much of our day to day activities-slower paced perhaps (at least at times), more introspective but both physically and mentally stimulating. Rapid prototyping and "trying things out"-"professional mucking about" as we jokingly refer to it in the lab, has been a staple of our research practice, so, for example, the Soma Bits and biosensing activities felt very familiar to us. The difference between our normal practice and this was the focus on unpacking sensation through the soma articulation techniques and through discussion-comparing 
the plurality of each other's soma experience in a structured and deep way. Having a focus less on rapidly programming experiences and more on just seeing what different things felt like was invigorating. Similarly, the sensitising activities-the bodyscans, Feldenkrais and Contact Improvisation were new to us as a practical methodology. Initially some of us felt a bit silly-especially with the Contact Improvisation as physically touching ones' colleagues is far from an everyday activity, but these activities definitely affected our way of thinking in the sessions. More broadly, since the workshop, we have incorporated many of these techniques into our practice, and we have multiple $\mathrm{PhD}$ students-and even some undergraduate projects-now applying Soma Design methodologies to their research. The regular discussions and some shared publications with the Soma Design studio since the workshop have encouraged us to embrace Soma Design well beyond what one might often expect from a two-day workshop.

\subsection{Reflections on the Workshop from the Soma Design Studio}

The Soma Design studio had given several workshops on Soma Design prior to this one, but mainly to industry partners. Conducting a Soma Design workshop with another research group with their own strong design program was new to us. We had also been reading about their design work for years, but this was the first time we really "felt" their aesthetic aims and what they were looking for. Feeling their aesthetic axioms came about step by step during the workshop. It became clear to us in how they would engage with certain experiences and not others, their ways of bringing in technology into the room-in particular VR, and their interest in sensory misalignments as a path to the uncomfortable. Applying Soma Design methods to explore a setting of a VR flying experience through a harness and a VR experience of walking in a balance beam were design contexts that pushed the aesthetic axioms of this method in new directions. This widened our understanding of how to apply Soma Design to other aesthetic aims, shifting us beyond body awareness. In particular, this has informed our more recent path towards understanding corporeal ethics and how ethics must not be confused with the nice or pleasant [22]. We also learnt how sensory misalignment can be a strategy to deepened somaesthetic appreciation [95], a practice we now use in our design work.

\section{DESIGN WORK}

\subsection{Case Study 1: the Balance Beam}

A first obvious point of departure for exploring the theme of balance was to create a balance beam. We constructed a physical balance beam from a scaffolding pole and rendered a facsimile of this in a virtual environment (see Figure 4). We aligned the two so that a person walking on the physical balance beam while wearing a VR headset could see the virtual beam in the virtual world as they felt the physical one through their feet. Beyond this main balance beam, a range of others were available for explorations, including a narrow pole and a $10 \mathrm{~cm}$ wide plank (as seen in Figure 4), which allowed for tuning the level of difficulty when balancing on the physical beam. Our VR application also allowed us to subtly rotate the visuals from behind the scenes, which made it more challenging to walk on and balance on the physical beam. Specifically the rotation was introduced as a participant's head moved further to the left or right orthogonal to the beam.

Aiming to explore how muscles are affected when changing states of balance, i.e., from being in balance to losing our balance and vice versa, participants placed an EMG sensor to the calf of those walking on the balance beam. The sensor consisted of three electrodes attached to a muscle on the participant's lower leg that acquired the EMG signal. The captured sensor data were then represented as a graph on a laptop screen. While viewing the sensor visualizations it was observed that it was possible to anticipate and predict the loss of balance shortly before the balancer actually 


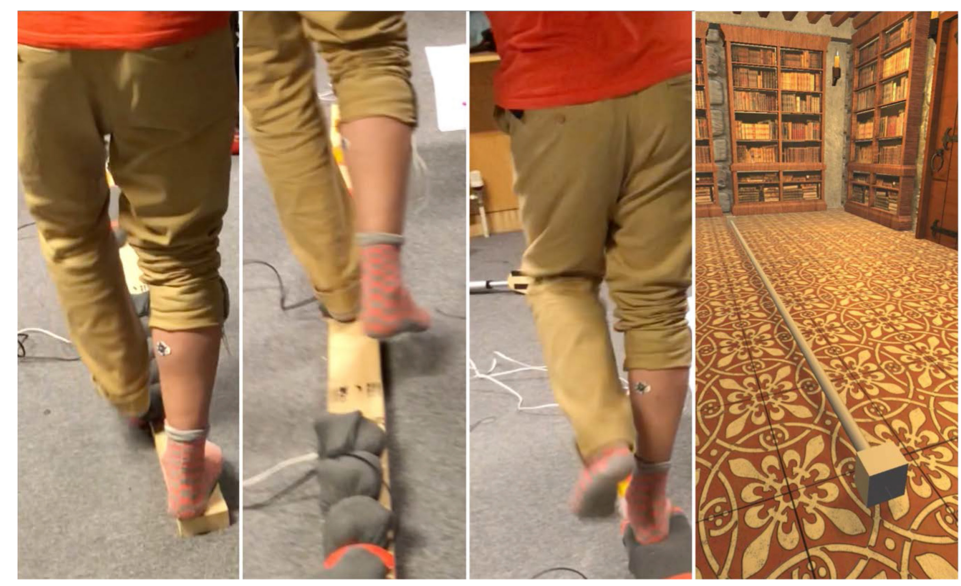

Fig. 4. Walking on the balance beam with EMG sensor attached to participant's lower leg.

fell off the beam. As a next step, we tested a sensor-actuator coupling of the EMG data of muscle contraction translated to a sound output, as a way of moving closer to the actual experience of being on and off balance through a focus on somatic aspects and felt sensations translated into sound (rather than looking at a laptop screen). Listening to these subtle contractions of the muscle captured through the EMG sensor offered a shared somatic experience of balance among all the participants in this group, while keeping a focus on this bodily activity.

Continuing explorations and reflections on somatic aspects of balance, participants started asking "How could balance be disrupted?" The first attempts had followed a geometrical approach, modifying the visuals in the VR [12]. However, the focus on Soma Design led participants to consider the contact points between the body and the prototype as possible disruption spots, and tried adding different Soma Bits to the feet touching the beam (Figure 4). The Soma Bits were used to stimulate the balancer's feet in diverse ways, through vibration effects, heat, textures and shapes, resulting in more noticeable differences in balance performance across participants. For example, one highly experienced balancer found himself entirely unable to balance when vibration was applied to his foot, and fell off repeatedly, whilst the same effect made little difference to others with less experience. Skilled balancers appeared to concentrate on completing the overall task of reaching the end of the beam rather than focusing on the fine details of balancing, and adding a level of interference to the "familiar" act of balancing through the Soma Bits disrupted this, calling their attention back to what their feet were doing which "felt" different and tended to cause them to fall off. Interestingly enough, heat actuation added to the end of the beam was perceived as a type of reward: as a positive feeling of success after managing to walk across the whole beamproviding a sense of relief or even catharsis-as reported in [95]. The VR balance beam experience has, since the workshop, been further developed and tested in exhibitions with many different users, to explore, for example, how different virtual environments and dynamic variations in the level of sensory misalignment can affect balancers crossing the beam. A detailed first person reflection of our experiences on the balance beam and the effects the various interventions we applied had on our ability to balance appears in our prior publication [95].

\subsection{Case Study 2: the Flying Harness}

Prior to the workshop, the Mixed Reality studio had built a flying harness prototype for testing flying simulation in virtual environments with the aim of enabling people to "fly like a superhero". 


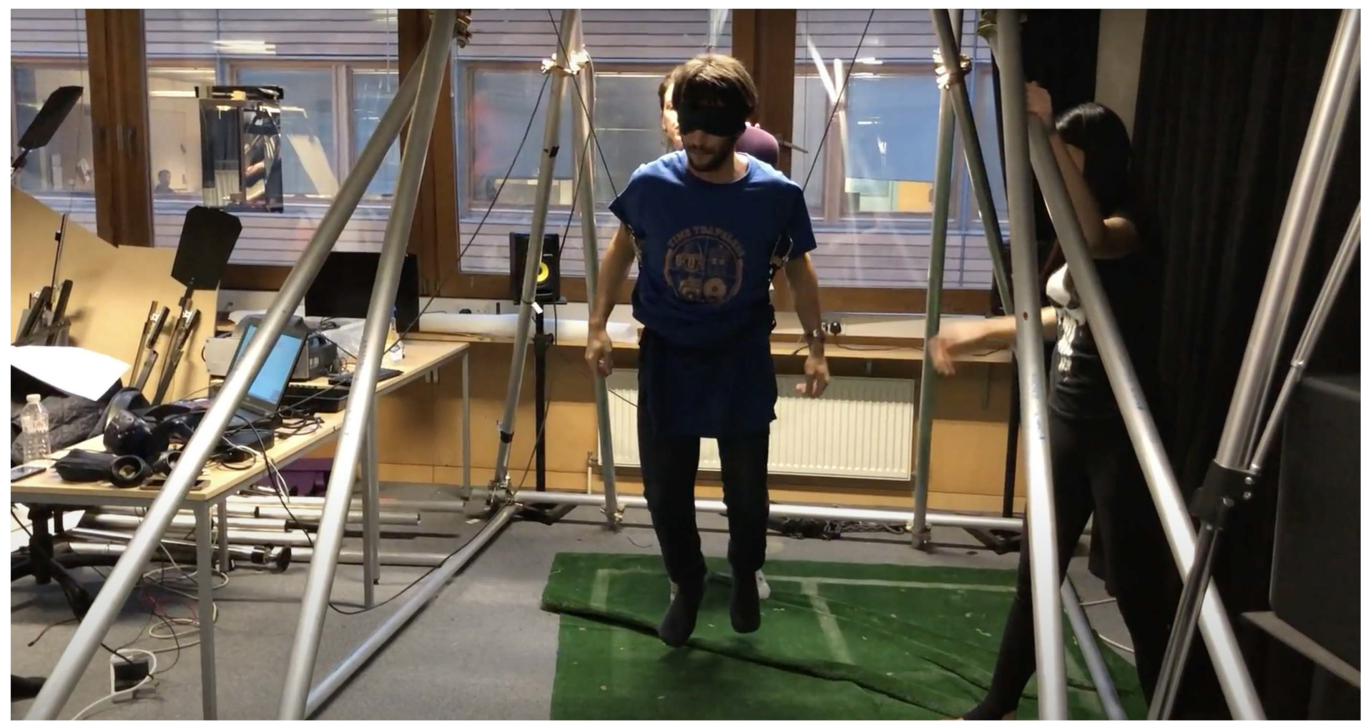

Fig. 5. Strapped on a flying harness while another participant is adding a big Soma shape on the back.

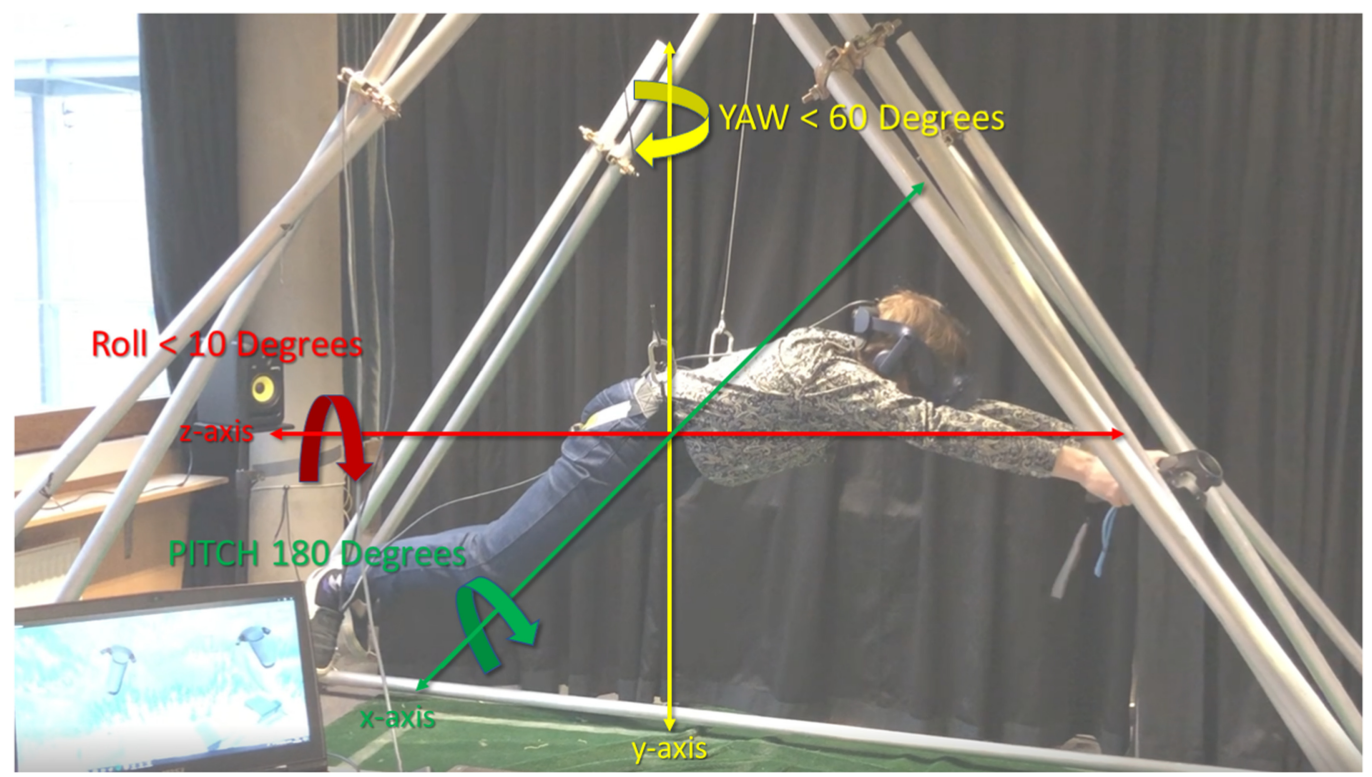

Fig. 6. Movement possibilities in the flying harness. Pitch allows at least 180 degree rotation, yaw, around 60 degrees, and roll less than 10 degrees.

The flying harness rig is a triangular structure stabilized firmly on the floor that has cables hanging and a crossbar with an attached harness that can be worn by one person (Figure 5). The harness is similar to those used in stage performances to make actors appear to fly. The wearer is suspended vertically at a few centimeters from the floor and supported. There are also movements that the flyer can perform such as turning their body upside-down (180 degrees) or twisting their body forwards or backwards (90 degrees), the rig allows for free pitch movement, some yaw movement and no roll, so these bodily movements are necessarily limited. Figure 6 shows a representation 
of how a flyer's movements are restricted. Donning a VR headset enables the flyer to use their bodily movement to control their flight through various virtual worlds, however, in order to limit the focus of activities to bodily sensation, the flying harness group elected to dispense with the VR headset and instead blindfold participants in the rig. This was done for two reasons-first, the practical reason that by removing the computational aspect of the VR, it wouldn't be necessary to spend time writing code to make any changes, and second, the group felt that by blindfolding the flyer, to remove visual cues about e.g., up/down, there might be opportunity to explore different kinaesthetic sensations.

The participants started by experimenting with different body postures and movements that one can perform while in the rig, paying close attention to the sensation of being suspended. The act in itself was not comfortable at all, as the safety measures required the harness to be firmly secured around the waist and the straps were tightly pressing the thighs and hips of the flyer. One had to make a constant physical effort, particularly to hang in a horizontal position, which affected the hips and put strain on these body parts, especially since the body weight was distributed over few points, making this setting particularly uncomfortable. But at the same time, participants found it enjoyable to be able to stretch their whole body. Moreover, this setting proved to be particularly interesting in light of somatic experiences, as it allowed for body postures, movements, body turns, and positions that are not usually performed while being on the floor, or when standing or sitting. Next, one group member at a time was suspended while the others assumed the role of supporting the flyer's experience. This included augmenting the suspended experience by adding various Soma Bits for supporting or hindering the flyer's movements, helping the flyer achieve any movements they were aiming for, and documenting these explorations.

Those explorations included adding various Soma Shapes (see Section 3.2 and Figure 3) and actuators to different parts of the flyer's body, aiming to enrich the harness experience. These led to examining how this (already unusual) activity could be altered, applying actuation modalities including heat and vibration on the back, the legs and the feet, among other places. The combination of being blindfolded, suspended on the harness, and the vibration on the back and along the spine led to sensory confusion in each of our participants who reported variations on feeling a wobbly sensation, like spinning around themselves [95]. No matter whether the flyer was going back and forth, rotating or holding a vertical position, the sensation appeared consistently across participants. Different metaphors were used to describe this experience, such as "feeling like an animal crawling on your back", as it was articulated by one member of the group.

The group also reflected on how the characteristics of the physical shapes, including softness and stiffness of the Soma Bits, could contribute to the experience. They questioned "how could the movements of suspended subjects be supported?" As it turned out, positioning Soma Shape surfaces at different spots on the body (e.g., hands, feet, and back) for the flyer to hold on to, or lean in to, created reference points of support and enabled further unexpected movements including twists, crawls, or climbs that would otherwise be impossible. It was noted that adding a reference point on the back, and especially one of the larger Soma Shapes depicted in Figure 3-in this case a cushioned shape of around $40 \times 40 \mathrm{~cm}$-seen being held against the back of the flyer in Figure 5 had a powerful impact on the flyer's somatic experience. This shape was experienced as being much bigger than it actually was, evoking feelings of "being extended" or feeling as if "someone is embracing you from the back".

\subsection{Case Study 3: the Augmented Guitar}

Prior to the workshop, researchers from the Mixed Reality studio had conducted ethnographic studies with guitarists practicing at home with digital resources. These studies reported that the flow of guitar playing, which is an embodied activity that requires skillful two-handed use, is 
constantly disrupted when engaging with computers during the performance preparation process [4]. Hence, for this group, the workshop was an opportunity to explore the underlying somatic experience of guitar playing and how they could keep guitar playing "in balance" when engaging with technology. We use the term "in balance" here more metaphorically than literally-"balancing" the mental and physical demands of playing the guitar with the mental and physical demands of interacting with technology and environment, though this group also explored the act of literally balancing while playing the guitar.

Within this group there were two participants that were proficient with guitar playing and two participants who had never played the guitar or had minimal experience but did not feel comfortable playing in front of other people.

The design work began by exploring the different parts of the body involved in guitar playing. These explorations involved touching and feeling the different bodily areas that become engaged when holding a guitar and keeping in balance when standing up, like the calves and the ankles for grounding the guitarists to the floor, but also the back, the shoulders, and the neck for maintaining a performance posture, and the points of contact between body and guitar, such as the torso and forearms, and finally the wrists and hands engaged in the mechanical task of guitar playing.

As a next step, participants started to experiment with different physical materials and Soma Bits by placing them on these bodily areas. At this stage participants repurposed an elastic resistance band (frequently used in yoga exercises) to use it as a stretchy guitar strap. This introduced specific bodily explorations with the elastic material like tugging down on the neck of the guitar and swaying the upper part of the body along with the instrument.

Another material exploration involved playing with the "cushy" Soma Shapes. These were cushioned boards stuffed with a soft filling so they could be easily deformed. In this case, participants experimented with stacking the boards on top of each other to craft a soft balancing board which they could step on and sway their bodies back and forth whilst playing guitar. The group also made low fidelity prototypes with the cushy shapes by stuffing them with materials such as rubber balls and vibration motors to simulate tangible interfaces and haptic feedback, respectively.

Both of these contraptions led participants to reflect on the dynamic qualities of balancing, and the different movements of the body involved. Using the strap and cushy balancing board encouraged smaller movements of the forearms and the feet while the guitarists swayed the guitar up and down or rocked their body back and forth. Moreover, the stretchy strap allowed the guitarists in the group to defamiliarise their habitual ways of holding and playing the guitar, while the cushy step in turn defamiliarised the postures associated with performance. The stretchy strap in particular directly impacted the "interface" to the guitar-changing the way the instrument and player are connected, and thus altering a deeply embedded relationship.

A series of design ideas emerged from this embodied ideation process (Figure 7). Stretching the strap could be employed as an interaction technique to modulate effects or generate sounds, as well as control media. Likewise, the cushy step could be used as a soft and deformable guitar pedalboard, which could also potentially control media or audio effects by balancing and swaying on the board or stroking its rugged texture (shaped by the rubber spheres underneath), it could also be employed to provide performance cues (such as tempo or rhythm) with haptic feedback through the feet.

Following the initial workshop, we ran a second workshop, this time focusing exclusively on guitars and continuing to explore the theme of tension and release involved when playing the guitar: The physical tension experienced throughout the different parts of the body engaged in guitar playing; the mental tension that emerges during live performance; the musical tension reflected in the build up and release in a musical piece; and the elastic properties the stretchy strap which may be tensed and released when stretched. This follow-up workshop focused mainly on the Stretchy 


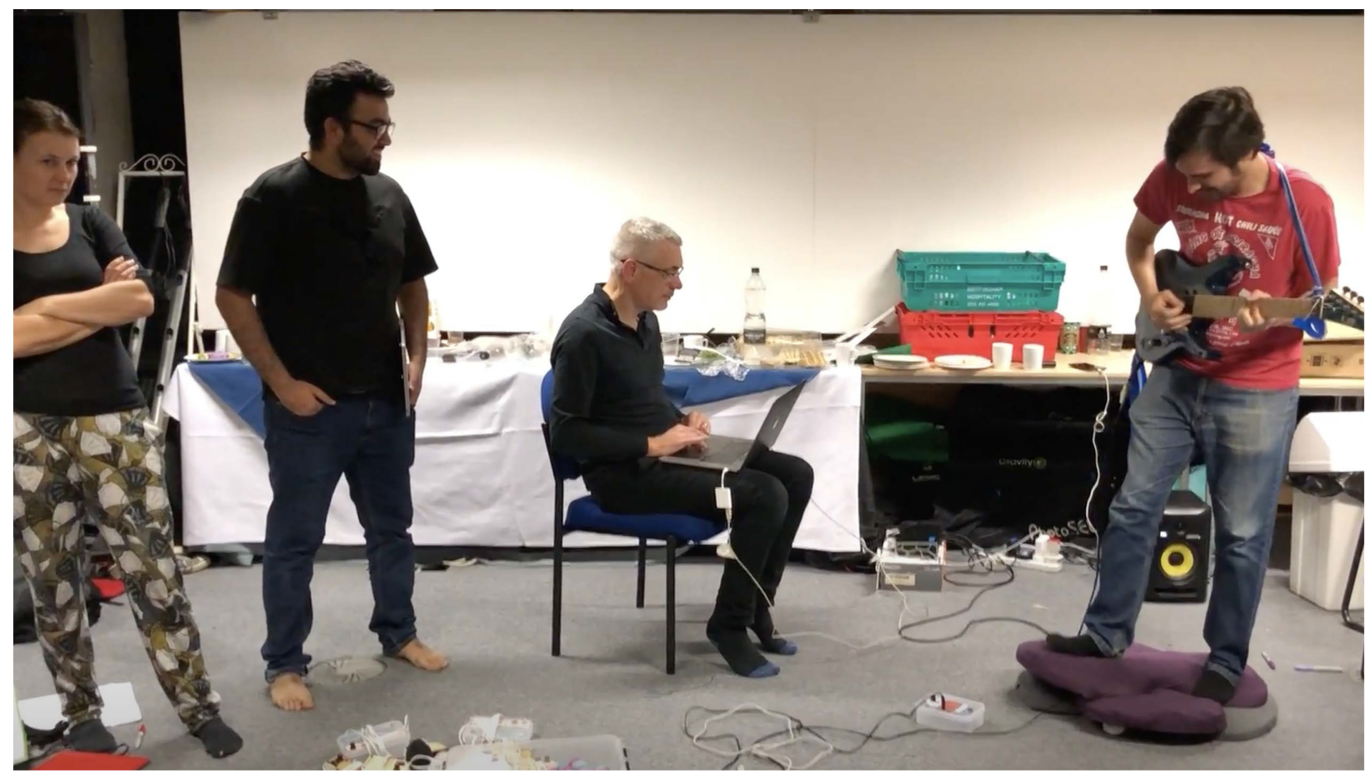

Fig. 7. Playing guitar with the stretchy strap and cushy pedals.

Strap, a design concept that we wished to take forward, but also explored the wider theme of guitar playing and Soma Design. It is described in detail in [5].

To enable non-guitarists to experience guitar playing with more ease we conducted several somatic facilitation experiments. For example, tuning the guitar to an open tuning so that chords could be easily performed by simply strumming the guitar-making it more accessible for participants without guitar playing expertise. With the same purpose, pairs made up of a guitarist and a non-guitarist would share a single guitar to allow the latter to simply strum the guitar while the former would perform the more complex action of fretting the notes. Another more radical approach involved a non-guitarist and a guitarist taping their fingers together so that the latter could experience the sensation of playing the guitar through the hand movements of the former. We should note that these experiments were not intended to convey years of guitar practice to a non-guitarist in a couple of hours but to allow them to feel some of the key sensations involved in guitar playing, allowing them to feel more comfortable in contributing their insights on guitar playing during the workshop.

Likewise, proficient guitarists were deliberately removed from their preconceptions of guitar playing by having their habitual bodily movements and internalized sensation of the guitar disrupted with the Soma Bits. In this case, actuators were placed on the fingers of the fretting hand of a guitarist, which had a numbing effect on the hand according to one of the guitarists. We also placed multiple inflatable cushions across the body of the guitar to create a sort of "breathing" guitar. One of these cushions was placed near the guitar's bridge, allowing us to observe how the expansion disrupted the accustomed sensations of the strumming hand, while others were placed on the back of the guitar and beneath the guitar strap, pressing against both on the stomach and shoulder of the guitar player when inflated.

One of the key design concepts that emerged from this exploratory process was the idea of an autonomously shape-shifting guitar that would inflate and deflate with the breathing patterns of the player, potentially helping them take deep breaths or slow down their breathing, and perhaps 
comforting them in those performance situations which produce some degree of anxiety in most players.

\subsection{Case Study 4: the Aesthetic Prosthetics}

This case study originated from a $\mathrm{PhD}$ research project to explore how 3D printing technologies could be used to manufacture aesthetic prosthetics for dancers, i.e., prosthetics that would enhance the aesthetics of a dance performance with respect to both movement and visual appearance. The aim of this research project is to enable the design and manufacture of artificial lower limbs for dancers that reflect the specific and personal requirements of dancing choreography, personal aesthetic taste, as well as mechanical and medical constraints. Prior to the workshop, the host research group had informally talked with several disabled dancers and found out that, while some do dance with a prosthesis, others prefer not to, for various reasons including prosthetics not feeling part of the dancer's body; the weight of prosthetics physically hindering the dancing performance; and an overall sense of prosthetics interfering in the aesthetics of dance. Thus the explorations during the workshop were mainly focused on what prosthetics might mean, be or doexploring the boundaries of the body, instead of focusing on concrete or final designs of actual prosthetic limbs. For this group, the goal for the workshop was to sensitise the participants as designers to the experience of dancers with a missing lower limb (either congenitally or following amputation) in advance of running a first collaborative workshop involving professional disabled dancers.

Prostheses cannot directly sense the dancer's surroundings in the same way that a human limb can, though they can of course still indirectly deliver sensations such as pressure to the points of the body where they are attached. Thus, a first challenge at the workshop was to obtain some sense of this altered bodily sensation. Feelings of touching points between feet and floor are crucial when dancers perform dancing motions and so were a natural starting point for the explorations conducted. In order to experience these differently, participants put very thick and soft sponges under their feet as they walked and performed other basic movements. The resulting sensations were unfamiliar and maintaining one's balance was a challenge, especially during rotation or jumping. Participants further noted a pervading numbness in their feet after some time doing these activities, leading them to question if sensations from the feet could be move "elsewhere". Inspired by previous research into enhancing the human body with false prosthetic tails [93] they tried shifting sensations from the feet to the upper leg. One such exploration included attaching a Soma Bits vibrator to the upper leg and manually activating this whenever the participant's foot touched the ground.

A second test explored differences in habits rather than in sensation. Dancers with missing lower limbs may exhibit quite different habitual ways of interacting with their surroundings compared to non-amputated ones. For instance, when a dancer with an amputated calf, especially one not wearing a prosthesis, stands, only a single leg is available for supporting the body, placing them in a permanent state of unstable equilibrium. Thus, the existing foot needs to keep subtly moving, and other parts need to constantly make adjustments, just in order to maintain balance. Similarly, for motions such as turning or jumping, disabled dancers may have to retrain themselves to acquire new habits that suit their bodies. In order to experience this first-hand, participants used elastic bands to constrain their limbs, e.g., connecting one calf to one arm so as to force the lower limb to bend and leave the ground. With this connection in place, participants were asked simply to stand and keep balance. Struggling against this constraint foregrounded their awareness of their own habitual movements as they undertook basic bodily movements, let alone dance, allowing them to imagine how their movement habits might be affected and altered should they have a missing lower limb (Figure 8). 


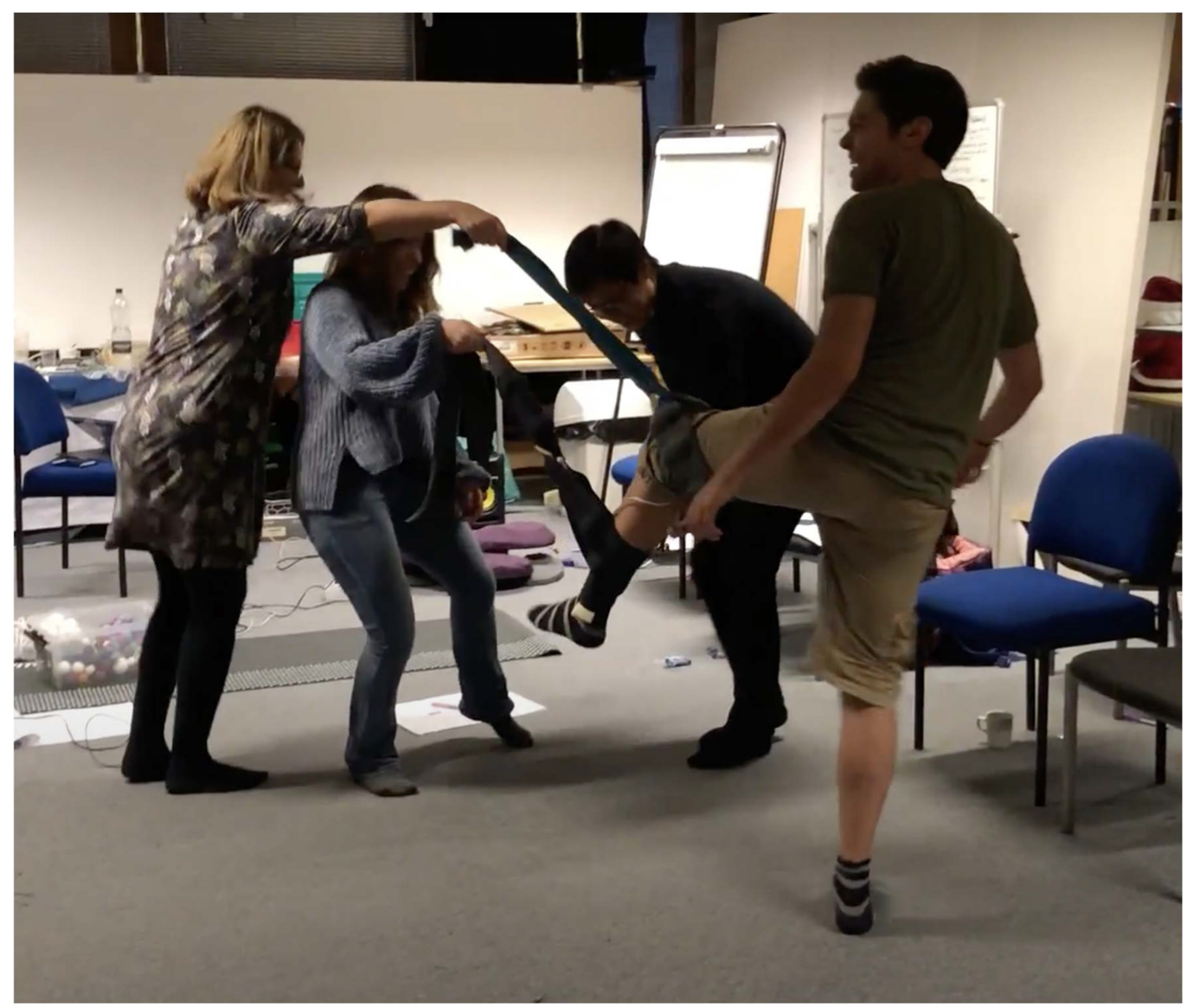

Fig. 8. Dancing with one limb while the other is connected to participants' arm.

The group then tried connecting one participant's calf with another's arm to allow for the sharing of sensations and also to give some experience with loss of control. The final exploration conducted during the workshop extended this to connect all four participants into a chain, where each person's calf was connected to another's arm. At first, it was a challenge just to keep in balance, since when standing on a single leg, any slight movement from one participant might trigger all of the whole to lose their balance. However, with time, participants were gradually able to keep their own balance, even if a neighbour was intent on disrupting it. The experience then became one of negotiating control back and forth between the various group members.

\section{PERSPECTIVES ON SOMA DESIGN}

As described earlier, a foundational principle of Soma Design is its holistic stance that invites us to reject dualistic and largely analytic views of the mind-body and instead to engage with mindbody through one's own practice. Soma Design can therefore be positioned as a first-person approach because it emphasises the personal and subjective appreciation of one's own bodily experience, that is, the bodily experience(s) of the designer(s). Our workshops provide many examples of how this first-person perspective came to the fore, from Feldenkrais exercises, to co-design sessions, to the use of body scans, all of which encourage participants to experience and appreciate their own 
bodily experiences in new ways. However, our workshops also reveal that it is deeply challenging to engage with such a broad holistic position. How can one simultaneously experience one's body and appreciate this in a new more aesthetic way? How can one's personal subjective experience be translated into designs for others? And how does Soma Design's holistic stance relate to wider conceptions of both body and mind that have influenced $\mathrm{HCI}$ ?

In the discussion that follows, we explore the idea of perspectives: that Soma Design involves adopting multiple perspectives on embodied interaction, but importantly that these are overlapping, in constant negotiation, and often simultaneous. Our discussion unfolds in three parts. First, we consider how Soma Design, while being grounded in first-person experience, requires us to negotiate first-, second-, and third-person perspectives. Second, we explore perspectives on the material body, considering how its boundaries extend both beyond the skin into the external world but also internally. Finally, we explore perspectives on the mind, relating Soma Design's non-dualistic stance to previous accounts of conscious and subconscious interaction that have been influential in $\mathrm{HCI}$.

\subsection{Perspectives on Design: Negotiating First, Second, and Third Person}

Soma designers often refer to Merleau-Ponty's [58] distinction between the first-person perspective of being inside an experience, feeling it as it unfolds, and the third-person perspective of seeing the body as an object in the world [92]. They also acknowledge the importance of second-person perspectives, for example, participant observation through kinesthetic empathy [26, 92]. The idea is that, as a designer, you move back and forth between these different perspectives during different phases of a design project. You might start out with a first-person perspective feeling balanced, but then, using a muscle-sensor turning movements into sound, you shift to a third-person perspective on your own body, noting how one specific muscle acts as you are about to fall off the balance beam, before then adopting a second-person perspective as you bring your personal experience to bear on the design of an experience for another.

Second- and third-person perspectives were also evident in our workshops. We often adopted third-person perspectives, viewing ourselves from outside of the scene to attune our aesthetic appreciation. We also considered users other than ourselves, be they imagined (as in our prosthetics example) or present (in the guitar example). However, what is more striking about our workshops is how these different perspectives were often held and negotiated simultaneously. During our sessions with Feldenkrais and the Soma Bits, participants were encouraged to engage in bodily practices while simultaneously reflecting upon new feelings. In the balance beam and guitar groups, both experts and novices negotiated second-person perspectives to understand each other as they simultaneously engaged in their own subjective experiences. Soma Design is therefore not only about moving between perspectives; first acting, then reflecting, then thinking of another (though this may happen), but rather is about trying to explore combinations of perspectives at the same time. This raises the key challenge of how we can we take something that is familiar, even habitual, and adopt a fresh perspective on it while actually practicing it?

5.1.1 Decoupling First- and Third-Person Perspectives. Making strange (sometimes called defamiliarization) is a common strategy to alter one's somaesthetic appreciation of the already familiar [102]. This process can be applied in many ways, from slowing down a habitual movement, to reversing one, to applying a sensory misalignment [95]. Defamiliarizing habitual movement patterns is a core principle in many somatic practices, based on the rationale that only by bringing to the surface what has become automatic and tacit can we change deeply ingrained, habitual patterns of movement (where movement should be seen in the most generic sense here-that is, everything from how you walk or sit to how you orient and bond socially with other people). Engaging in 
strangeness lets you discern small changes to your ongoing experience, noting exactly how sensations in the body relate to your emotional experiences, to feel enjoyment or pain in all the small nuances of what those sensations bring [7, 79, 102]. In theories of somaesthetics [87], it is argued that by exploring and zooming in our habitual ways of moving or breathing, such as by trying alternative ways of breathing or even holding our breath, we can train ourselves to learn to appreciate the aesthetics of our own soma and, ultimately, our experiences of the world, through uncovering what is hidden in habit.

In the workshops, we performed Feldenkrais activities that focused on making an attentional shift towards body parts and sensations that might not normally be considered when performing the later design activities in the session. These exercises employed various strategies to encourage participants to simultaneously explore both first- and third-person perspectives.

Changing the speed of a movement is one way to create defamiliarization. Several exercises involved slowing down movements while considering the interconnectedness of the various associated body parts, leading to explicit sensitisation. However, speed change works in both directions; sometimes we want to speed activities up. Tongue-twisters play on this-simply saying a phrase becomes increasingly difficult and unfamiliar as we speed it up-something also made use of in many songs, especially call and response songs like Cab Calloway's Minnie the Moocher.

A second defamiliarization strategy involves reversing a habitual movement, such as interlacing your fingers in the non-habitual way-putting the other thumb on top. As you do, both the habitual and the non-habitual ways of interlacing your fingers come into focus, in turn letting you examine the details and nuances of the experience-which parts of your fingers touch? Where are the palms of your hands? Is one hand slightly more dominant than the other? Is one hand bigger? Such reversals need not simply apply to movements, but also to activities. Leading onto the balance beam with your non-dominant foot, for example, completely changes the way we initially negotiate our balance and allows us to confront the process from a fresh perspective.

The further strategy of exposing autonomic or semi-autonomic systems such as breathing can also lead to interesting defamiliarizations. Breathing is an activity which is largely autonomic, happening in the background of our attention, but many activities such as yoga or meditation encourage us to actively breathe and to consider how we are breathing. Different emotions and stress are mirrored in the intricate patterns of breathing: when we focus, we sometimes stop breathing; when we are stressed, we breathe in a shallow manner; when we are sad, we may sigh; and when we are physically tired from exercise we may take deep breaths to recover. Once attention is drawn to such a semi-autonomic activity, it becomes strange as we are unable to deliberately background it again. This foregrounding of background bodily activities can be very explicit, with breathing, for example, in $[9,59,96]$. In the second guitar workshop, we asked one of the participants to observe his own breathing as he played a difficult piece of music, and he noticed how he breathed irregularly or altered his breathing pattern. From these experiences, the breathing guitar concept arose [5]. A breathing guitar could, for example, mirror breathing back to the guitarist to help increase awareness of tensions. By exposing the player's breathing pattern or even by subsequently taking control over the breathing pace, as with Moran et al.'s ExoPranayama [59], a breathing guitar could induce relaxation and thereby improve performance. Underlying the design here is also the idea that players might ultimately refamiliarise themselves with new interactions, perhaps embedding them into their practice and ultimately performance as part of a process of breaking old habits and forming new ones.

A final strategy involved moving between comfortable and uncomfortable experiences. As articulated by Benford et al. [8]: "uncomfortable interactions are those that cause a degree of suffering to the user. This may be physical suffering such as physical stress, tiredness or pain, but might also involve mental suffering due to fear and anxiety, either experienced directly or 
empathetically on behalf of others." (p.2005). Uncomfortable interactive experiences, as discussed by the same authors, could potentially enhance entertainment, support both within-group social bonding and between-group social bridging by means of shared or recognised experience [74], or even contribute to personal enlightenment by demanding a deep personal commitment when engaging in an interactive experience, similar to experiencing interactive artworks [8]. Our design sessions and explorations in each group often focused on uncomfortable somatic experiences as a way of raising awareness to first-person experiences through estrangement, while at the same creating a space for sharing such experiences with one-another. In particular we explored how sensory misalignment using technology disturbing the visual sense, but also misaligning other senses with one-another could lead to insight, as we have reported on elsewhere [95].

A similar approach is also possible with other fully autonomic bodily processes over which we cannot exert direct control. For example, in our workshop we looked at the effect on balance when sonifying EMG data from one's calf muscles. This brought attention to that specific muscle area, which in turn defamiliarized the task, since typically the attention is not on the actions of our muscles but our holistic "feeling" of balancing-that is-when we walk a balance beam, we are not thinking "am I extending or contracting my calf muscle here?” rather we may just change the position of our leg or hips to keep us balanced. This requires the actions of several different muscles-none of which we attend to directly. This exposure of autonomic bodily activity often requires an external intervention-such as the application of the EMG sensor, and such (external) interventions can more generally be powerful tools for creating defamiliarization. In the guitar example, we taped expert players' fingers together to make the instrument strange to them-providing constraints to the normal pathways in a movement pattern and again leading us to focus on the bodily sensations of the task, and foregrounding the doing of a habitual activity for which one has expertise and muscle memory. The flying harness group used blindfolding to focus the flyer's senses more on touch, inner-ear balance and proprioception, while the prosthetics group wrapped a cord around one participant's leg and attached it to the arm of another participant as they danced, to create a sensation of a limb having a mind of its own.

5.1.2 Decoupling First- and Second-Person Perspectives. We also applied these various strategies in collaborative situations which led to a decoupling of first- and second-person perspectives. The initial Feldenkrais exercises were sometimes conducted between pairs, with one person touching and moving the other's body in unusual ways while both attended to the resulting sensations, and the Contact Improvisation dance sessions asked participants to act in groups of four or five, engaging in joint movements and making it unclear where one body started and the next began This general approach was then carried over into subsequent co-design sessions. The guitar group wrestled with the challenge of bridging between different levels of expertise; some participants were relative experts in playing the guitar, but novices in Soma Design, while others were expert soma designers but novice guitarists. Various strategies were adopted for bridging this gap, such as strange duets in which one expert player performed the fingering whilst a novice strummed the strings. In a similar vein, the prosthetics group's use of strings to connect their bodies foregrounded a consideration of another's perspective in interaction.

Generally, defamiliarizing an activity can help shift our perspective from expert to novice, forcing us to confront the early challenges associated with performing an action that might be all but automatic in everyday life. Writing with the non-dominant hand is a trivial change to undertake, but has a substantial impact on writing ability. Similarly, flipping a guitar over to play with the opposite hands-coincidentally also reversing the order of the strings-can turn an expert guitarist into a novice. We explored other examples of activity defamiliarization in the guitar group, such as having participants play strange duets using only one hand each or taking away the sound of 
the instrument to focus attention away from making music and more on less familiar aspects of the bodily experience such as posture, movement, and breathing while playing. Such strategies encourage us to question our habitual expertise in our own everyday actions and to consider them afresh from a more second-person perspective.

Our analysis also helps us see how thought processes, norms, socially ready made practices, or somatic expertise such as the ability to play the guitar, are interlinked with movement and bodily experiences to such an extent that it is only when we "upset" them that they can come into focus, be disentangled and available for change and for design. The various tactics of defamiliarization were not only aimed at designers and the design process, but also found their way into the end-user experience. The breathing guitar, for example, is designed to take the player (the end user) on their own somatic journey by defamiliarizing the instrument in order to foreground typically neglected aspects of interaction, such as breathing. In short, strategies for temporarily defamiliarizing one's own habitual expertise can apply to expert practitioners who wish to improve their own somatic experiences as much as they do to designers. Such activities may be of less value to novices simply because the skill itself is unfamiliar-for example, it's probably not desirable to disrupt the somatic process of playing the guitar when we are not already familiar with that process, though we may wish to disrupt the process for the purpose of making the strange familiar.

Much of what we have seen so far has focused on defamiliarization, in making the familiar strange. However, we should also consider the reverse of this process, how might we take an activity with which we are unfamiliar and make it seem more familiar. For the tightrope, the steel beam was replaced with a wider wooden plank to reduce the difficulty of the task, allowing the novices to feel as if they were performing the same activity. VR enhanced this by showing the visual appearance of a tightrope, even when just walking across the floor. The flying harness example was one with which nobody was familiar. Both the harness itself and the VR activity of flying were strange experiences, but the harness made flying less strange as the sensation matched expectations (i.e., one's feet were not on the floor). For the prosthetics group, this activity was perhaps the hardest since none of the participants actually wore a prosthesis and thus weren't familiar with their use. The approach taken was to use a familiar activity (dance), then go through a process of defamiliarizing that activity, using "stand-in" prosthetics (e.g., the limb attached to another participant), but foregrounding the dance rather than the prosthesis.

It is apparent that familiarity is a spectrum, where we may be more or less familiar with an activity, we may be more or less familiar with the bodily actions and sensations associated with that activity and by intervention we can change our position on that spectrum. Through making the familiar strange, we open a perspective gap, a looseness of imaginations, a space of sorts between first-, second-, and third-person perspectives, that can be filled with design ideas, imaginations of novel experiences, and possible interactions.

Movement from familiar to strange to refamiliarized, is therefore not a straight line, but an ongoing process, flowing back and forth. The process of learning, discovering, and deepening aesthetic appreciation continues into the use of the designed system. Every time the guitarist turns to his breathing while playing the breathing guitar, he may discover something new. Defamiliarization tactics relate to and influence our overall attitude, making us more open, more attentive, more willing to probe what can be changed, ultimately leading to a richer repertoire of experiences and to deeper aesthetic appreciation skills. When this change of attitude is spurred, be it during the design process or deliberately included in the final design, the resulting process is enriching for both designer and end-user, highlighting and exposing the connections between movement, emotion, thought and action, helping us recognise the holistic complexity of our designs and interactions and the non-dualist nature of how we experience them. 


\subsection{Perspectives on the Mind: Designing with and Through Kinesthetic Experience}

HCI has traditionally been greatly concerned with the mind, often adopting a cognitive perspective on interaction. Of particular relevance here is recent work that has explored the relationship between what could broadly be characterised as the conscious and subconscious elements of our interaction with computers which underpins approaches such as persuasive computing, implicit interactions, and mindless computing. We described earlier how the separation of what Kahneman refers to as "automatic mind" (system 1) and "reflective mind" (system 2) thinking [45](2011) has been influential in HCI, from the early emergence of Direct Manipulation Interfaces through to more recent developments in persuasive computing [71], mindless computing [1], and implicit interactions [83]. Our experience of Soma Design speaks to the distinction between system 1 and system 2 thinking in a quite different way than these approaches. Our interest is not in mindless or implicit engagements with systems that may go unnoticed by their users, but rather in drawing attention to bodily experience. Thus, we aim to engage system 1 and system 2 thinking together in order to enrich our aesthetic appreciation of our bodily experience. In our workshops we were typically attempting to ward off other interests, keeping ourselves focused and attentive towards what is going on in our system 1 . At the same time we were often feeding our nervous system with novel kinesthetic experiences, such as moving in a non-habitual way or feeling what a vibration bit applied on the shoulder might do. By applying the ideas of William James pertaining to attention and interest [42], we then probe and interrogate the experience, in a sense keeping our system 2 busy with attending to this inner universe without disturbing the experience.

In essence, what Soma Design asks us to do is to attend to the fast, automatic frequent, unreflected system 1 with a different attitude-using the reflective, slower, mindful system 2 . From the outside, it might seem as if Soma Design is mainly a process of acutely active awareness, one where the soma designer has to focus intently on the somatic signs and signals in order to make them clearer and attainable for design ideas and crafting. But, the more important difference to embodied interaction is how somaesthetics, beyond discerning and understanding those experiences, also aims to improve on them. By attending to and training our awareness, the somaesthetic appreciation of what is happening can be altered towards better functioning or more interesting experiences. This shifts us from analytically understanding how an embodied interaction unfolds into providing a direction for design-to improve on our aesthetic appreciation.

Turning to our workshops, our guitar example illustrates the complex ways in which Soma Design can shape the aesthetic appreciation of bodily experience. A key element of learning a musical instrument involves dedicated learning of physical techniques through instruction or experimentation and then habituating these through repeated practice so that they become automatic during performance. However, it is not so much that the skilled musician becomes unaware of their body playing music, but more that their attention becomes directed towards other more aesthetic aspects of their performance, perhaps interpretation, phrasing, performative gestures, or even dance like movements, more than the physical mechanics of precisely how their fingers are moving. This process of shifting attention to different aspects of playing music has been documented in detail by David Sudnow in his auto-ethnography of learning to play jazz piano during in which he reported coming to see his own hands in new ways [91]. The relationship between physical action and aesthetic appreciation can also become problematic however. Musicians who are nervous about performing in public may revert to thinking about how they move their fingers, which may actually interfere with their ability to play. This phenomenon is also reported in sport [98], for example, this is known as getting "the yips" in golf. Also problematic is that poor physical technique can become deeply habituated. Breathing is important to playing the guitar, including as a way of relaxing and so coping with performance nerves, although many guitarists neglect this as it is not a primary aspect of engaging the instrument (as it would be with a wind instrument). 
Our low-fi explorations of "cushy pedals" and "stretchy straps" sought to refocus the guitarist's attention on their posture, overall bodily movement, and contact with the ground rather than on their fingers. Similarly, our breathing guitar prototype aims to dynamically redirect the player's attention towards different aspects of their bodily experience, from their own breathing patterns to awareness of their hands on the neck of the instrument.

In summary, analytically understanding how these processes are enacted in human cognition is interesting and important to our understanding of interaction design. But as Shusterman points out, a pragmatist position is not solely an analytical one, but also a pragmatic and practical engagement. For interaction designers, our aim is always to bring out novel experiences, novel designs. Our pragmatic and practical engagements need to be generative to design [37]. Hummels and colleagues propose that design should be done through moving [40], without any translation inbetween, but it is never as simple as taking an experience and designing for it. At some level, there will always be a need for articulating and sharing experience-and most importantly the potential for novel experiences as we add technology into the loop. Above, we mentioned how defamiliarisation methods not only allow us to make somatic reactions clearer in our minds, attainable for scrutiny, but also renew capacity for fresh sensations, allowing for novel kinesthetic design ideas. Discussing and sharing these ideas in a design team requires bringing others into the same spaceto share the experience, to re-create it for another team member, and to recognise the plurality of our subjective experiences of the same activity in order to know whether and how we can reliably design for it. The orchestration of events and interactions through technological interactions need to come together into a whole, be tested and repeatedly "felt" by the team members even if each person's unique soma will colour and introduce variability. It becomes a process of designing with and through kinesthetic experience together.

\subsection{Perspectives on the Body: from Inside to the Outside and from Body to Tech}

So far we have talked about how Soma Design requires designers (and potentially users too) to simultaneously explore multiple perspectives on their embodied experience. But what is it that we are taking a perspective on? What constitutes embodied experience? Our workshops challenged how we might think of bodily experience in $\mathrm{HCI}$ and especially the boundaries of the body itself.

Our review of related work introduced various perspectives that challenge conventional dualistic thinking about the separation of the physical body from the wider material world; from established notions of embodied intelligence and situated action $[86,90]$ to more radical views that embrace the merging of the body with digital technologies [14] or with the wider material world [10]. Such perspectives were evident in our workshops where questions concerning the boundaries of the body emerged in different ways, mainly as a reflective and to some extent speculative topic in each project group. For example, when we sonify the movement of our muscles (as in the balance beam) and then that sonification affects our balance, to what extent does the sensor, the laptop, and the speaker become part of our bodily process?

In the case of the Balance Beam, since VR technology was a central aspect of the explorations in this group, the perspective of "inside" vs "outside" the body emerged in relation to how visualisations contributed to the overall felt, somatic experience of walking on the tightrope, and thus expanding the boundaries of the soma. Specifically, participants reflected on how "wobble visualisations" felt like sensory stimulation becoming "part of the body" as it was replacing one's "normal vision". In that case, external, visual stimuli was perceived as rather "internal". And more broadly, the overall choreographed experience of sensory misalignment wrapped up in redirected walking, was described by some of the participants as being a very "intrusive" and to some extent overwhelming experience. There was a presence and participation of the whole soma in the experience evoked through the combination of the VR visualisations, the balance beam, and the 
heat and vibration actuators integrated on the beam-including the "inside" and the "outside" soma participating in that experience.

In the case of the Flying harness there were similar reflections to the Balance Beam group, but focusing more on haptic stimuli instead of visual ones. The unique experience of being both suspended and blindfolded proved to be a fruitful situation and context for questioning the boundaries between soma and technology on the one hand, but also the boundaries between the inside and outside of the actual soma. Being blindfolded put a strong focus on the "inside", which in that context refers to the felt experiences and sensations foregrounded through the soma explorations that were conducted in this group. The experience of putting different shapes of the Soma Bits toolkit on the person being suspended and blindfolded, evoked a sensation of "blurred boundaries between where the body ends and where it begins", as explicitly articulated by one participant. Placing soma shapes of different sizes to different areas on the body of the suspended person also made that person question "who is putting the shapes on you?" Participants shared their experiences of feeling that it could be another person putting shapes manually, or that it could be the actual flying harness, "the machine" putting different shapes on one's soma. Through the expanded understanding of where the body ends and where is begins, they speculated on a flying harness prototype designed in a way that it could place shapes to different areas on the suspended person's body, for supporting or hindering particular bodily movements when being immersed in the flying harness VR experience, or even placing shapes to suggest one where to move next. Beyond the physical soma shapes placed on the body, when they were combined with actuators (heat, vibration), they also contributed to an expanded understanding of the boundaries of the soma. One example here was that when vibration was applied to the back of the person being suspended and blindfolded, there was a feeling of spinning around oneself, causing an experience of a sensory misalignment. This in turn evoked an experience of blurred boundaries between "inside" and "outside", especially when vibration was applied on the spine (and on bone structures more broadly), which caused a soma experience of feeling as if the vibration was coming from the inside of one's body. This experience led to further speculating on the possibility of placing actuators inside the body, instead of outside, i.e., next to the skin.

Playing with the inside-outside dichotomy was also present in the Prosthetics group, and it was possibly more central in this group, compared to the others. As mentioned earlier in the article, in their design process they played with a conceptual configuration of connecting multiple bodies through their prosthetic limbs, expanding on the idea of considering prosthetics as a solely individual and personal body extension, to one that extends to, and connects many bodies together. When one body moves, the others move too as bodies are interconnected, but no one is really in control, since the boundaries between who is leading and who is following, but also where a body ends and where it begins, become blurred. Through the experience of their bodies being interconnected to one another, they reflected on uncomfortable experiences of being off-balance, but also on how to be playful and cultivate trust among one another. For example, by having others push and pull on one's leg during a dance performance through a distributed prosthetic limb, one can feel the other bodies and be supported through them. Throughout the workshop, participants used the term "distributed agency" to reflect on who is in control of that experience, but also to further speculate on who could possibly be in control: is it solely one dancer that initiates a movements for the whole "collaborative body" comprised many dancers through their joint prosthetic limbs? Or is it the interactive prosthetic extension that initiates a movement first, which the dancer(s) would choose whether to follow? Or is it an autonomous system in control, or the choreographer, or other limbs in a loop? The design explorations in the Prosthetics group moved to exploring the quality of intimate correspondence [89] among many bodies (dancers) and many prosthetic limbs, where the line between bodies and prosthetics (materials) becomes blurred, all acting on, reacting 
to and re-acting on one another in correspondence with one-another. This may mirror the individual findings on awareness of prosthesis in [62] in which Murray notes that both awareness of, and attention required by, prostheses diminishes with time.

In the case of the Guitar group, participants explored the quality of "implicit control" between soma and guitar, through which they questioned the boundaries between instrument and soma. They focused on interactions with the guitar as an external object that is not part of one's actual body, but which is held very closely to it and so has an intimate relationship with the player's body. One reflection that emerged from the first workshop and became a central topic of exploration in the second, was that a guitar can already feel a bit like an extension of the body-especially when bevelled and moulded to it. Through the concept of the Breathing Guitar prototype developed in the second workshop participants pushed at the boundaries between the guitar as an artifact and the player's body, recognising a sense of "being one" with the guitar when playing. They also managed to push the interaction a bit more internally as the breathing guitar engages with the stomach and ribs and the internal sensation of breathing.

Reflecting across these examples, we see that, once again, in seeking to adopt a holistic perspective on bodily interactions, designers need to negotiate multiple and shifting perspectives, this time on what the body might be. Our experiences challenged simple dichotomies between "inside" and "outside" or "human" and "machine", suggesting that the boundaries between humans and computers can be treated as being liminal and open to new challenges and opportunities at the meeting between the two. In some cases, such as the balance beam and flying harness, this liminality concerns the relationship between the body as traditionally conceived and what lies beyond its skin in the material world. In others, such as the breathing guitar, the focus of design turns inwards to consider the autonomic systems that lie under the skin. In others, such as prosthetics, our experiences focus on the treatment of digital technologies as being visible body parts. Questioning the boundaries between humans and technology also invites for questioning and reflecting on the boundary between our own "inside" and "outside", separated by the skin: breathing in and out, ingesting and excreting. Thinking through these boundaries allows designers to re-define them, and thus challenge where the soma begins and where it ends, but also where the boundaries of experience lie.

\section{CONCLUSION}

Soma Design has emerged as a new approach to the design of embodied interaction, an increasingly important thread within HCI. Soma design's distinctiveness as an approach lies in its claims to be holistic-challenging the dualistic mind-body thinking that has underpinned much of $\mathrm{HCI}$ for many decades-but also that it is grounded in first-person bodily experience and oriented towards establishing a heightened aesthetic appreciation of such experience. This combination of concerns makes Soma Design a somewhat mysterious proposition, including for the team at Mixed Reality studio who engaged in our workshops alongside the Soma Design studio. While a holistic stance sounds appealing, what does this mean in practice? How can one design the particular details of an interaction while also considering the whole experience? While designing through firstperson experience may be appealing, how can one then connect this to designing for others? And how might an aesthetic appreciation of one's own bodily experience differ from other kinds of appreciation?

We have reported how we explored the mysteries of Soma Design though a series of joint workshops and subsequent reflections between our two studios, both of whom were exploring embodied interactions, albeit with different agendas. By unpacking and detailing the creative work the two studios have done together, we attempt to demystify the non-dualism claim of Soma Design. There were some immediate practical outcomes from our joint work in the form of four quite different 
design explorations, several of which have matured into longer term developments. However, the main reflective contribution set out in this article has been to reconsider the nature of holism and dualisms, in Soma Design specifically and in embodied interaction more generally.

We have come to recognise that Soma Design involves negotiating multiple perspectives on bodily experience, perspectives that often represent different dualisms. However, rather than treating them as fixed dualisms, these perspectives are more fluid and flexible and are often held simultaneously-much in the way Merleau-Ponty writes about the "double sensations" of being inside our bodies at the same time as we watch them from the outside, or the "felt" experience of the other at the same time as feeling our own experience. In the design process, they act like lenses that can be temporarily picked up and used to see the whole of embodied interaction in a new light before then being set aside again. In that process, a Soma Design view will always recognise and foreground the lived, felt experience. Our article has contributed various examples of doing this.

First, we have negotiated various design perspectives. One of these is between one's own bodily experience (first-person) and a more analytic stance in which one reflects on your own body as an object (third-person)-even if we never can escape the "double sensation" of being in that body. Our experience shows how this perspective may be negotiated through various defamiliarisation strategies which invite us to both engage in bodily practices while simultaneously achieving a heightening and altered appreciation of them. A second is between one's own experience (the firstperson perspective) and that of another (the second-person perspective). These defamiliarisation strategies let us engage in what Husserl framed as intersubjective reduction, in which we "participate in the other's positing" [78]. Again, various defamiliarisation strategies, but this time applied collaboratively, enabled us to bridge the perspective gap between expert and novice designers and practitioners, unsettling the expert's habitual body to let the novice part-take in the experience.

Second, we have negotiated three mindbody perspectives. One is the separation of mind from body. A second is the separation of the conscious mind from the subconscious mind (so called system 1 and system 2 ) and the third is the separation of the physical body from the wider material world, including the world within the body itself. Again, in our experience of Soma Design, these are not rigid dualisms, but rather fluid perspectives that can be continually negotiated through bodily experience.

We have shown how this ongoing negotiation of perspectives can be achieved through de- and re-familiarisation. Our article has unpacked why we engage with the non-habitual or strange to open the gaps within and between these perspectives that can then be filled with novel somasensory experiences. We have shown how we attend to our inner universe and attempt to dissolve the dichotomies between inside and outside, individual and other, body and technology, thereby traversing several dualistic divisions.

In doing this, Soma Design takes an active stance. A key aim is to improve on the designer's ability to discern and appreciate all the details of an experience, which in turn may shape the experience for the end users as one of attending to and deepening their own appreciation of the experience. We have shown how to ward off distractions in order to attend and remain interested ultimately learning to appreciate the aesthetics of our somas' signs and signals. The four examples from our workshops reveal various ways in which we as soma designers undertook journeys back and forth across different perspectives in order to attune or design sensitivities so as to hopefully lead us to become better designers. However, it is also evident that our designs might directly encourage our users to undertake similar journeys in order to develop their own abilities to have better experiences. Learning to dance, play the guitar, walk a tightrope, or even fly (albeit in a harness) all involve continually refining aesthetic appreciation through bodily practice and so the various negotiation strategies we have set out might potentially be part of the designs we produce as well as being part of the design process. 
Finally, we note a further way in which Soma Design's deconstruction of bodily experience differs from other approaches. Both the mind-body dualism and conscious-subconscious (system 1-system 2) approaches adopt what might be thought of as a "horizontal" approach in which the problem of designing bodily interactions with computers can be considered as spanning different layers of abstraction, albeit with complex inter-dependencies. Mind and body can be seen as separate layers of the self. System 1 and system 2 can be seen as separate layers of the mind that are connected through persuasive technologies that break or reform habits. We propose that Soma Design takes a more "vertical" approach in which bodily experience is broken down into different parts of the body that temporarily become the focus of attention, while also considering how they connect to other body parts as part of a holistic experience. Feldenkrais exercises, body scans, contact improvisation, and the Soma Bits are instrumental in calling attention to particular combinations of body parts as part of negotiating our various perspectives. Soma design, in this sense, bears a stronger resemblance with phenomenological and in particular micro-phenomenological accounts of experience $[17,85]$ mentioned in the background. But where micro-phenomenology uses introspection to analyse experiences from the past, the retentions Husserl referred to, soma design has a different purpose. Our aim is not to analyse the lived experience, but to design for it, alter it, bring users through a journey where somaesthetic experiences are woven into a whole that allows for meaning-making, aesthetic experience, and learnings that are of relevance to the purpose (or task) of the design, be it playing the guitar, balancing on a tightrope, flying in a harness, or dancing with a prosthesis.

Similar to other first-person research methods, the reliability of the Soma Design methods discussed here can be questioned, as introspection comes with the risk of distorting or disrupting experience. We used several approaches to articulate the somaesthetic experiences: we used defamiliarisation methods to make the lived experiences clearer in our minds; we used body sheets that we filled in before and after an experience; we engaged in verbalisations and discussions in the design teams; we constructed semi-finished prototype experiences facilitated by the Soma Bits to let others potentially experience what we had felt; and so on. All these forms of articulation and journeys through overlapping first-, second-, and third-person perspectives may potentially disturb the experience or fail to capture all the nuances we seek. Furthermore, the reliability of the somaesthetic experiences we report on can be questioned. Soma Design methods should be validated by criteria such as whether they are generative to design; whether the resulting designs reliably sustain the somaesthetic user experience sought; and so on. The detailed analysis provided here contributes mainly towards unpacking how Soma Design is enacted, demystifying its non-dualistic design claims, and showing how that in turn differs from other HCI work. Other forms of unpacking is needed to prove its validity.

In conclusion then, pursuing Soma Design's holistic and aesthetic agenda has led us to confront several dualisms that run like fault lines through HCI's engagement with embodied interaction. We have ended up treating these as perspectives, ways of temporarily and simultaneously viewing the whole of bodily interaction-the soma-in a way that can open up a creative space for new design ideas to enhance aesthetic appreciation.

\section{REFERENCES}

[1] Alexander T. Adams, Jean Costa, Malte F. Jung, and Tanzeem Choudhury. 2015. Mindless computing: Designing technologies to subtly influence behavior. In Proceedings of the 2015 ACM International foint Conference on Pervasive and Ubiquitous Computing. Association for Computing Machinery, New York, NY, 719-730. DOI : https://doi.org/10. $1145 / 2750858.2805843$

[2] Miquel Alfaras, Vasiliki Tsaknaki, Pedro Sanches, Charles Windlin, Muhammad Umair, Corina Sas, and Kristina Höök. 2020. From biodata to somadata. In Proceedings of the 2020 CHI Conference on Human Factors in Computing Systems. Association for Computing Machinery, New York, NY, 1-14. DOI : https://doi.org/10.1145/3313831.3376684 
[3] Josh Andres, M. C. Schraefel, Rakesh Patibanda, and Florian 'Floyd' Mueller. 2020. Future InBodied: A framework for inbodied interaction design. In Proceedings of the 14th International Conference on Tangible, Embedded, and Embodied Interaction. Association for Computing Machinery, New York, NY, 885-888. DOI : https://doi.org/10.1145/3374920. 3374969

[4] Juan Pablo Martinez Avila, Chris Greenhalgh, Adrian Hazzard, Steve Benford, and Alan Chamberlain. 2019. Encumbered interaction: A study of musicians preparing to perform. In Proceedings of the 2019 CHI Conference on Human Factors in Computing Systems. Association for Computing Machinery, New York, NY, 1-13. DOI: https: //doi.org/10.1145/3290605.3300706

[5] Juan P. Martinez Avila, Vasiliki Tsaknaki, Pavel Karpashevich, Charles Windlin, Niklas Valenti, Kristina Höök, Andrew McPherson, and Steve Benford. 2020. Soma design for NIME. In Proceedings of the International Conference on New Interfaces for Musical Expression, Romain Michon and Franziska Schroeder (Eds.). Birmingham City University, Birmingham, 489-494. Retrieved from https://www.nime.org/proceedings/2020/nime2020_paper93.pdf.

[6] Madeline Balaam, Nadia Campo Woytuk, Marianela Ciolfi Felice, Ozgun Kilic Afsar, Anna Ståhl, and Marie Louise Juul Søndergaard. 2020. Intimate touch. Interactions 27, 6 (Nov. 2020), 14-17. DOI : https://doi.org/10.1145/ 3427781

[7] Genevieve Bell, Mark Blythe, and Phoebe Sengers. 2005. Making by making strange: Defamiliarization and the design of domestic technologies. ACM Transactions on Computer-Human Interaction 12, 2 (June 2005), 149-173. DOI: https: //doi.org/10.1145/1067860.1067862

[8] Steve Benford, Chris Greenhalgh, Gabriella Giannachi, Brendan Walker, Joe Marshall, and Tom Rodden. 2012. Uncomfortable interactions. In Proceedings of the SIGCHI Conference on Human Factors in Computing Systems. Association for Computing Machinery, New York, NY, 2005-2014. DOI : https://doi.org/10.1145/2207676.2208347

[9] Steve Benford, Richard Ramchurn, Joe Marshall, Max L. Wilson, Matthew Pike, Sarah Martindale, Adrian Hazzard, Chris Greenhalgh, Maria Kallionpää, Paul Tennent, and Brendan Walker. 2020. Contesting control: Journeys through surrender, self-awareness and looseness of control in embodied interaction. Human-Computer Interaction 0, 0 (2020), 1-29. DOI : https://doi.org/10.1080/07370024.2020.1754214

[10] Jane Bennett. 2010. Vibrant Matter: A Political Ecology of Things. Duke University Press.

[11] Frederik Brudy, Christian Holz, Roman Rädle, Chi-Jui Wu, Steven Houben, Clemens Nylandsted Klokmose, and Nicolai Marquardt. 2019. Cross-Device taxonomy: Survey, opportunities and challenges of interactions spanning across multiple devices. In Proceedings of the 2019 CHI Conference on Human Factors in Computing Systems. Association for Computing Machinery, New York, NY, 1-28. DOI : https://doi.org/10.1145/3290605.3300792

[12] Richard Byrne, Joe Marshall, and Florian Floyd Mueller. 2018. AR fighter: Using HMDs to create vertigo play experiences. In Proceedings of the 2018 Annual Symposium on Computer-Human Interaction in Play. Association for Computing Machinery, New York, NY, 45-57. DOI : https://doi.org/10.1145/3242671.3242689

[13] Nadia Campo Woytuk, Marie Louise Juul Søndergaard, Marianela Ciolfi Felice, and Madeline Balaam. 2020. Touching and being in touch with the menstruating body. In Proceedings of the 2020 CHI Conference on Human Factors in Computing Systems. Association for Computing Machinery, New York, NY, 1-14. DOI : https://doi.org/10.1145/3313831 3376471

[14] Manfred E. Clynes and Nathan S. Kline. 1995. Cyborgs and Space. In The Cyborg Handbook, C. H. Gray (Ed.). Routledge London, 29-34.

[15] Antonio R. Damasio. 2006. Descartes' Error. Random House.

[16] Stanislas Dehaene, Jean-Pierre Changeux, Lionel Naccache, Jérôme Sackur, and Claire Sergent. 2006. Conscious, preconscious, and subliminal processing: A testable taxonomy. Trends in Cognitive Sciences 10, 5 (2006), $204-211$.

[17] Natalie Ed Depraz, Francisco J. Varela, and Pierre Ed Vermersch. 2003. On Becoming Aware: A Pragmatics of Experiencing. John Benjamins Publishing Company.

[18] René Descartes. 2008. 1641. Meditations on first philosophy (with selections from the objections and replies). Translation by M. Moriarty. 3-62.

[19] John Dewey. 2005. Art as Experience. Penguin.

[20] Paul Dourish. 2004. Where The Action Is: The Foundations of Embodied Interaction. MIT press.

[21] Elizabeth A. Duke, WF Hicken, WSM Nicoll, DB Robinson, and JCG Strachan. 1995. Plato. Oxford University Press.

[22] Sara Eriksson, Kristina Höök, Richard Shusterman, Dag Svanes, Carl Unander-Scharin, and Åsa Unander-Scharin. 2020. Ethics in movement: Shaping and being shaped in human-drone interaction. In Proceedings of the $2020 \mathrm{CHI}$ Conference on Human Factors in Computing Systems. Association for Computing Machinery, New York, NY, 1-14. DOI : https://doi.org/10.1145/3313831.3376678

[23] Umer Farooq and Jonathan Grudin. 2016. Human-computer integration. Interactions 23, 6 (Oct. 2016), 26-32. DOI : https://doi.org/10.1145/3001896

[24] Umer Farooq and Jonathan T. Grudin. 2017. Paradigm shift from human computer Interaction to Integration. In Proceedings of the 2017 CHI Conference Extended Abstracts on Human Factors in Computing Systems. Association for Computing Machinery, New York, NY, 1360-1363. DOI : https://doi.org/10.1145/3027063.3049285 
[25] Moshe Feldenkrais. 1972. Awareness through Movement. Vol. 1977. New York: Harper and Row.

[26] Jules Françoise, Yves Candau, Sarah Fdili Alaoui, and Thecla Schiphorst. 2017. Designing for kinesthetic awareness: Revealing user experiences through second-person inquiry. In Proceedings of the 2017 CHI Conference on Human Factors in Computing Systems. Association for Computing Machinery, New York, NY, 5171-5183. DOI: https://doi. org/10.1145/3025453.3025714

[27] Gabriel Frey, Arno Jurkschat, Safak Korkut, Jonas Lutz, and Rolf Dornberger. 2019. Intuitive hand gestures for the interaction with information visualizations in virtual reality. In Proceedings of the Augmented Reality and Virtual Reality. Springer, 261-273.

[28] Jen Jack Gieseking, William Mangold, Cindi Katz, Setha Low, and Susan Saegert. 2014. The People, Place, and Space Reader. Routledge.

[29] Brian Gleeson, Karon MacLean, Amir Haddadi, Elizabeth Croft, and Javier Alcazar. 2013. Gestures for industry intuitive human-robot communication from human observation. In Proceedings of the 2013 8th ACM/IEEE International Conference on Human-Robot Interaction. IEEE, 349-356.

[30] Kayla J. Heffernan, Frank Vetere, Lauren M. Britton, Bryan Semaan, and Thecla Schiphorst. 2016. Insertable digital devices: Voluntarily under the skin. In Proceedings of the 2016 ACM Conference Companion Publication on Designing Interactive Systems. Association for Computing Machinery, New York, NY, 85-88. DOI : https://doi.org/10.1145/ 2908805.2913026

[31] Niels Henze, Andreas Löcken, Susanne Boll, Tobias Hesselmann, and Martin Pielot. 2010. Free-hand gestures for music playback: Deriving gestures with a user-centred process. In Proceedings of the 9th International Conference on Mobile and Ubiquitous Multimedia. 1-10.

[32] John Augustus Hicks. 1907. Cap-feeding machine. US Patent 845,415.

[33] Kristina Höök. 2008. Affective loop experiences - what are they? In Proceedings of the 3rd International Conference on Persuasive Technology. Springer-Verlag, Berlin, 1-12. DOI : https://doi.org/10.1007/978-3-540-68504-3_1

[34] Kristina Höök. 2018. Designing with the Body: Somaesthetic Interaction Design. MIT Press.

[35] Kristina Höök, Baptiste Caramiaux, Cumhur Erkut, Jodi Forlizzi, Nassrin Hajinejad, Michael Haller, Caroline Hummels, Katherine Isbister, Martin Jonsson, George Khut, Lian Loke, Danielle M. Lottridge, Patrizia Marti, Edward Melcer, Florian Müller, Marianne Graves Petersen, Thecla Schiphorst, Elena Márquez Segura, Anna Ståhl, Dag Svanæs, Jakob Tholander, and Helena Tobiasson. 2018. Embracing first-person perspectives in soma-based design. Informatics 5, 1 (Feb. 2018), 8. DOI : https://doi.org/10.3390/informatics5010008

[36] Kristina Höök, Martin P. Jonsson, Anna Ståhl, and Johanna Mercurio. 2016. Somaesthetic appreciation design. In Proceedings of the 2016 CHI Conference on Human Factors in Computing Systems. Association for Computing Machinery, New York, NY, 3131-3142. DOI : https://doi.org/10.1145/2858036.2858583

[37] Kristina Höök and Jonas Löwgren. 2012. Strong concepts: Intermediate-level knowledge in interaction design research. ACM Transactions on Computer-Human Interactions 19, 3 (Oct. 2012), Article 23, 18 pages. DOI: https: //doi.org/10.1145/2362364.2362371

[38] Johanna Höysniemi, Perttu Hämäläinen, Laura Turkki, and Teppo Rouvi. 2005. Children's intuitive gestures in vision-based action games. Communications of the ACM 48, 1 (Jan. 2005), 44-50. DOI : https://doi.org/10.1145/1039539. 1039568

[39] Yuhan Hu, Sang-won Leigh, and Pattie Maes. 2017. Hand development kit: Soft robotic fingers as prosthetic augmentation of the hand. In Proceedings of the Adjunct Publication of the 30th Annual ACM Symposium on User Interface Software and Technology. Association for Computing Machinery, New York, NY, 27-29. DOI : https://doi.org/10.1145/ 3131785.3131805

[40] Caroline Hummels and Kees Overbeeke. 2010. Special issue editorial: Aesthetics of interaction. International fournal of Design 4, 2 (2010).

[41] Katherine Isbister and Florian "Floyd" Mueller. 2015. Guidelines for the design of movement-based games and their relevance to HCI. Human-Computer Interaction 30, 3-4 (2015), 366-399. DOI : https://doi.org/10.1080/07370024.2014. 996647

[42] W. James. 1890. The principles of psychology, Vol. 1. New York, NY: Henry Holt and Co. (1890).

[43] Lars-Erik Janlert and Erik Stolterman. 2015. Faceless interaction-a conceptual examination of the notion of interface: Past, present, and future. Human-Computer Interaction 30, 6 (2015), 507-539. DOI : https://doi.org/10.1080/07370024. 2014.944313 arXiv:https://doi.org/10.1080/07370024.2014.944313

[44] Wendy Ju and Larry Leifer. 2008. The design of implicit interactions: Making interactive systems less obnoxious. Design Issues 24, 3 (2008), 72-84.

[45] Daniel Kahneman. 2011. Thinking, Fast and Slow. Macmillan.

[46] Michael Karlesky and Katherine Isbister. 2016. Understanding fidget widgets: Exploring the design space of embodied self-regulation. In Proceedings of the 9th Nordic Conference on Human-Computer Interaction. Association for Computing Machinery, New York, NY, Article 38, 10 pages. DOI : https://doi.org/10.1145/2971485.2971557 
[47] George (Poonkhin) Khut. 2016. Designing biofeedback artworks for relaxation. In Proceedings of the 2016 CHI Conference Extended Abstracts on Human Factors in Computing Systems. Association for Computing Machinery, New York, NY, 3859-3862. DOI : https://doi.org/10.1145/2851581.2891089

[48] George Poonkhin Khut, Angie Morrow, and Melissa Yogui Watanabe. 2011. The BrightHearts project: A new approach to the management of procedure-related paediatric anxiety. In Proceedings of the OzCHI Workshop Program.

[49] Scott R. Klemmer, Björn Hartmann, and Leila Takayama. 2006. How bodies matter: Five themes for interaction design. In Proceedings of the 6th Conference on Designing Interactive systems. 140-149.

[50] David Koteen, Nancy Stark Smith, and Steve Paxton. 2008. Caught Falling: The Confluence of Contact Improvisation, Nancy Stark Smith, and Other Moving Ideas. Contact Editions.

[51] Ellen J. Langer. 2000. Mindful learning. Current Directions in Psychological Science 9, 6 (2000), 220-223.

[52] Joseph LeDoux. 1998. The Emotional Brain: The Mysterious Underpinnings of Emotional Life. Simon and Schuster.

[53] Sang-won Leigh, Harshit Agrawal, and Pattie Maes. 2018. Robotic symbionts: Interweaving human and machine actions. IEEE Pervasive Computing 17, 2 (2018), 34-43. DOI : https://doi.org/10.1109/MPRV.2018.022511241

[54] Lian Loke and Thecla Schiphorst. 2018. The somatic turn in human-computer interaction. Interactions 25, 5 (Aug. 2018), 54-5863. DOI : https://doi.org/10.1145/3236675

[55] Attalan Mailvaganam and Miguel Bruns Alonso. 2015. Haptic beats: Designing for rich haptic interaction in a music controller. Design and semantics of form and movement (2015), 184.

[56] Joe Marshall, Florian 'Floyd' Mueller, Steve Benford, and Sebastiaan Pijnappel. 2016. Expanding exertion gaming. International fournal of Human-Computer Studies 90 (2016), 1-13. DOI : https://doi.org/10.1016/j.ijhcs.2016.02.003

[57] Joe Marshall and Paul Tennent. 2017. Touchomatic: Interpersonal touch gaming in the wild. In Proceedings of the 2017 Conference on Designing Interactive Systems. Association for Computing Machinery, New York, NY, 417-428. DOI : https://doi.org/10.1145/3064663.3064727

[58] Maurice Merleau-Ponty and Colin Smith. 1969. Phenomenology of perception. Routledge.

[59] Stuart Moran, Nils Jäger, Holger Schnädelbach, and Kevin Glover. 2016. ExoPranayama: A biofeedback-driven actuated environment for supporting yoga breathing practices. Personal and Ubiquitous Computing 20, 2 (April 2016), 261-275. DOI : https://doi.org/10.1007/s00779-016-0910-3

[60] Florian 'Floyd' Mueller, Darren Edge, Frank Vetere, Martin R. Gibbs, Stefan Agamanolis, Bert Bongers, and Jennifer G. Sheridan. 2011. Designing sports: A framework for exertion games. In Proceedings of the SIGCHI Conference on Human Factors in Computing Systems. Association for Computing Machinery, New York, NY, 2651-2660. DOI : https://doi.org/ 10.1145/1978942.1979330

[61] Florian Floyd Mueller, Pedro Lopes, Paul Strohmeier, Wendy Ju, Caitlyn Seim, Martin Weigel, Suranga Nanayakkara, Marianna Obrist, Zhuying Li, Joseph Delfa, Jun Nishida, Elizabeth M. Gerber, Dag Svanaes, Jonathan Grudin, Stefan Greuter, Kai Kunze, Thomas Erickson, Steven Greenspan, Masahiko Inami, Joe Marshall, Harald Reiterer, Katrin Wolf, Jochen Meyer, Thecla Schiphorst, Dakuo Wang, and Pattie Maes. 2020. Next steps for human-computer integration. In Proceedings of the 2020 CHI Conference on Human Factors in Computing Systems. Association for Computing Machinery, New York, NY, 1-15. DOI : https://doi.org/10.1145/3313831.3376242

[62] Craig D. Murray. 2004. An interpretative phenomenological analysis of the embodiment of artificial limbs. Disability and Rehabilitation 26, 16 (2004), 963-973.

[63] Michael Nielsen, Moritz Störring, Thomas B. Moeslund, and Erik Granum. 2003. A procedure for developing intuitive and ergonomic gesture interfaces for HCI. In Proceedings of the International Gesture Workshop. Springer, 409-420.

[64] Donald A. Norman. [n.d.]. Cognitive engineering. In User Centered System Design: New Perspectives on HumanComputer Interaction, D. A. Norman and S. W. Draper (Eds.). Lawrence Erlbaum Assoc, Hillsdale, NJ.

[65] Donald A. Norman. 1999. Affordance, conventions, and design. Interactions 6, 3 (May 1999), 38-43. DOI : https://doi. org/10.1145/301153.301168

[66] Steve Paxton. 1975. Contact improvisation. The Drama Review: TDR 19, 1 (1975), 40-42. Retrieved from http://www. jstor.org/stable/1144967.

[67] Ekaterina Peshkova, Martin Hitz, and David Ahlström. 2016. Exploring user-defined gestures and voice commands to control an unmanned aerial vehicle. In Proceedings of the International Conference on Intelligent Technologies for Interactive Entertainment. Springer, 47-62.

[68] M. Petersen, Ole Iversen, P. Krogh, and M. Ludvigsen. 2004. Aesthetic interaction: A pragmatist's aesthetics of interactive systems. In Proceedings of the Conference on Designing Interactive Systems: Processes, Practices, Methods, and Techniques.

[69] Claire Petitmengin, Anne Remillieux, and Camila Valenzuela-Moguillansky. 2019. Discovering the structures of lived experience. Phenomenology and the Cognitive Sciences 18, 4 (Sept. 2019), 691-730. DOI : https://doi.org/10.1007/s11097018-9597-4

[70] Rosalind W. Picard. 2000. Affective Computing. MIT press. 
[71] Charlie Pinder, Jo Vermeulen, Benjamin R. Cowan, and Russell Beale. 2018. Digital behaviour change interventions to break and form habits. ACM Transactions on Computer-Human Interaction 25, 3 (June 2018), Article 15, 66 pages DOI : https://doi.org/10.1145/3196830

[72] Martin Porcheron, Joel E. Fischer, Stuart Reeves, and Sarah Sharples. 2018. Voice interfaces in everyday life. In Proceedings of the 2018 CHI Conference on Human Factors in Computing Systems. Association for Computing Machinery, New York, NY, 1-12. DOI : https://doi.org/10.1145/3173574.3174214

[73] Mirjana Prpa, Sarah Fdili-Alaoui, Thecla Schiphorst, and Philippe Pasquier. 2020. Articulating experience: Reflections from experts applying micro-phenomenology to design research in HCI. In Proceedings of the 2020 CHI Conference on Human Factors in Computing Systems. Association for Computing Machinery, New York, NY, 1-14. DOI : https: //doi.org/10.1145/3313831.3376664

[74] Robert D. Putnam . 2000. Bowling Alone: The Collapse and Revival of American Community. Simon and schuster.

[75] Johan Redström. 2017. Making Design Theory. MIT Press.

[76] Dean Rubine. 1992. Combining gestures and direct manipulation. In Proceedings of the SIGCHI conference on Human factors in computing systems. 659-660.

[77] Pedro Sanches, Axel Janson, Pavel Karpashevich, Camille Nadal, Chengcheng Qu, Claudia Daudén Roquet, Muhammad Umair, Charles Windlin, Gavin Doherty, Kristina Höök, and Corina Sas. 2019. HCI and affective health: Taking stock of a decade of studies and charting future research directions. In Proceedings of the 2019 CHI Conference on Human Factors in Computing Systems. Association for Computing Machinery, New York, NY, 1-17. DOI : https: //doi.org/10.1145/3290605.3300475

[78] Bob. Sandmeyer. 2007. The basic problems of phenomenology. from the lectures, winter semester, 1910-11 (review) Journal of the History of Philosophy 45, 2 (2007), 338-339. DOI : https://doi.org/10.1353/hph.2007.0047

[79] Thecla Schiphorst. 2007. Really, really small: The palpability of the invisible. In Proceedings of the 6th ACM SIGCHI Conference on Creativity \& Cognition. Association for Computing Machinery, New York, NY, 7-16. DOI : https://doi. org/10.1145/1254960.1254962

[80] Thecla Schiphorst. 2011. Self-Evidence: Applying somatic connoisseurship to experience design. In Proceedings of the CHI'11 Extended Abstracts on Human Factors in Computing Systems. Association for Computing Machinery, New York, NY, 145-160. DOI : https://doi.org/10.1145/1979742.1979640

[81] Thecla Schiphorst, Renata Sheppard, Lian Loke, and Chyi-Cheng Lin. 2013. Beautiful dance moves: Mapping movement, technology \& computation. In Proceedings of the 9th ACM Conference on Creativity \& Cognition. Association for Computing Machinery, New York, NY, 429-433. DOI : https://doi.org/10.1145/2466627.2487289

[82] Thecia Henrietta Helena Maria Schiphorst. 2009. The Varieties of User Experience Bridging Embodied Methodologies from Somatics and Performance to Human Computer Interaction. University of Plymouth.

[83] Albrecht Schmidt. 2000. Implicit human computer interaction through context. Personal Technologies 4, 2 (2000), 191-199.

[84] Barış Serim and Giulio Jacucci. 2019. Explicating "Implicit Interaction" An examination of the concept and challenges for research. In Proceedings of the 2019 CHI Conference on Human Factors in Computing Systems. 1-16.

[85] Jonathan Shear and Francisco J. Varela. 1999. The View from Within: First-person Approaches to the Study of Consciousness. Imprint Academic.

[86] Maxine Sheets-Johnstone. 1999. The Primacy of Movement. John Benjamins Pub.

[87] Richard Shusterman. 2008. Body Consciousness: A Philosophy of Mindfulness and Somaesthetics. Cambridge University Press.

[88] Richard Shusterman. 2015. Somaesthetics. Retrieved October 2, 2020 from https://www.interaction-design.org/ literature/book/the-encyclopedia- of-human-computer-interaction-2nd-ed/somaesthetics.

[89] Anna Ståhl, Martin Jonsson, Johanna Mercurio, Anna Karlsson, Kristina Höök, and Eva-Carin Banka Johnson. 2016. The soma mat and breathing light. In Proceedings of the 2016 CHI Conference Extended Abstracts on Human Factors in Computing Systems. Association for Computing Machinery, New York, NY, 305-308. DOI : https://doi.org/10.1145/ 2851581.2889464

[90] Lucy A. Suchman. 1987. Plans and Situated Actions: The Problem of Human-Machine Communication. Cambridge university press.

[91] David Sudnow. 1993. Ways of the Hand: The Organization of Improvised Conduct. MIT Press.

[92] Dag Svanæs and Louise Barkhuus. 2020. The designer's body as resource in design: Exploring combinations of pointof-view and tense. In Proceedings of the 2020 CHI Conference on Human Factors in Computing Systems. Association for Computing Machinery, New York, NY, 1-13. DOI : https://doi.org/10.1145/3313831.3376430

[93] Dag Svanaes and Martin Solheim. 2016. Wag your tail and flap your ears: The kinesthetic user experience of extending your body. In Proceedings of the 2016 CHI Conference Extended Abstracts on Human Factors in Computing Systems. Association for Computing Machinery, New York, NY, 3778-3779. DOI : https://doi.org/10.1145/2851581.2890268 
[94] Paul Tennent and Steve Benford. 2019. Twenty years of the mixed reality laboratory. In Proceedings of the Extended Abstracts of the 2019 CHI Conference on Human Factors in Computing Systems. Association for Computing Machinery, New York, NY, 1-4. DOI : https://doi.org/10.1145/3290607.3313280

[95] Paul Tennent, Joe Marshall, Vasiliki Tsaknaki, Charles Windlin, Kristina Höök, and Miquel Alfaras. 2020. Soma design and sensory misalignment. In Proceedings of the 2020 CHI Conference on Human Factors in Computing Systems. Association for Computing Machinery, New York, NY, 1-12. DOI : https://doi.org/10.1145/3313831.3376812

[96] Paul Tennent, Duncan Rowland, Joe Marshall, Stefan Rennick Egglestone, Alexander Harrison, Zachary Jaime, Brendan Walker, and Steve Benford. 2011. Breathalising games: Understanding the potential of breath control in game interfaces. In Proceedings of the 8th International Conference on Advances in Computer Entertainment Technology. Association for Computing Machinery, New York, NY, Article 58, 8 pages. DOI : https://doi.org/10.1145/2071423.2071496

[97] Richard H. Thaler and Cass R. Sunstein. 2009. Nudge: Improving Decisions About Health, Wealth, and Happiness. Penguin.

[98] Jakob Tholander and Stina Nylander. 2015. Snot, sweat, pain, mud, and snow: Performance and experience in the use of sports watches. In Proceedings of the 33rd Annual ACM Conference on Human Factors in Computing Systems. Association for Computing Machinery, New York, NY, 2913-2922. DOI : https://doi.org/10.1145/2702123.2702482

[99] Vasiliki Tsaknaki, Madeline Balaam, Anna Ståhl, Pedro Sanches, Charles Windlin, Pavel Karpashevich, and Kristina Höök. 2019. Teaching soma design. In Proceedings of the 2019 on Designing Interactive Systems Conference. Association for Computing Machinery, New York, NY, 1237-1249. DOI : https://doi.org/10.1145/3322276.3322327

[100] Muhammad Umair, Corina Sas, and Muhammad Hamza Latif. 2019. Towards affective chronometry: Exploring smart materials and actuators for real-time representations of changes in arousal. In Proceedings of the 2019 on Designing Interactive Systems Conference. Association for Computing Machinery, New York, NY, 1479-1494. DOI : https://doi. org/10.1145/3322276.3322367

[101] Ron Wakkary, Audrey Desjardins, and Sabrina Hauser. 2016. Unselfconscious interaction: A conceptual construct. Interacting with Computers 28, 4 (2016), 501-520.

[102] Danielle Wilde, Anna Vallgårda, and Oscar Tomico. 2017. Embodied design ideation methods: Analysing the power of estrangement. In Proceedings of the 2017 CHI Conference on Human Factors in Computing Systems. Association for Computing Machinery, New York, NY, 5158-5170. DOI : https://doi.org/10.1145/3025453.3025873

[103] Charles Windlin, Anna Ståhl, Pedro Sanches, Vasiliki Tsaknaki, Pavel Karpashevich, Madeline Balaam, and Kristina Höök. 2019. Soma bits-mediating technology to orchestrate bodily experiences. In Proceedings of the Research through Design Conference 2019, the Science Centre, Delft, on 19th to 22nd March 2019. DOI : https://doi.org/10.6084/m9.figshare. 7855799.v2

Received October 2020; revised February 2021; accepted April 2021 